\title{
Managerial delegation theory revisited
}

\section{Luciano Fanti • Luca Gori • Mauro Sodini}

\begin{abstract}
This paper challenges the results of the "classical" managerial delegation literature, where it is assumed that the weight of the managerial bonus only depends on the owner's will to maximise his own profits. By considering sales (S) (resp. relative profit (RP)) contracts, the received literature has found that $(\mathrm{S}, \mathrm{S})(\mathrm{resp} .(\mathrm{RP}, \mathrm{RP}))$ is the unique pure-strategy sub-game perfect Nash equilibrium in a game that contrasts $\mathrm{S}$ (resp. RP) with pure profit maximisation (PM). This paper shows that none of the previous results may not hold when the owner negotiates about managerial compensation with his manager.
\end{abstract}

Keywords Bargaining; Managerial delegation; Quantity competition

JEL Classification D43; J53

L. Fanti

Department of Economics and Management, University of Pisa, Via Cosimo Ridolfi, 10, I-56124 Pisa (PI), Italy e-mail: luciano.fanti@unipi.it

tel.: +390502216 369; fax:+390502210603

L. Gori (corresponding author)

Department of Political Science, University of Genoa, Via Balbi, 30/19, I-16126 Genoa (GE), Italy

e-mail: luca.gorieunige.it or dr. luca.goriegmail. com

tel.: +39010 20995 03; fax: +390102095536

M. Sodini

Department of Economics and Management, University of Pisa, Via Cosimo Ridolfi, 10, I-56124 Pisa (PI), Italy e-mail: mauro.sodini@unipi.it

tel.: +390502216 234; fax: +39050 2210603 


\section{Introduction}

In the second half of the 1980s, Vickers (1985), Fershtman and Judd (1987) and Sklivas (1987), VFJS for short, provided a new strategically based reason to explain the observed non-profitmaximising behaviour of managers (sales or revenue delegation), in addition to those already established by the managerial economics and agency theory in the preceding years (Baumol, 1958, Holmström, 1982). By resorting to a modern game-theoretic approach, VFJS argued that ownership and control might be separated, essentially to let managers behave more aggressively in the market and force rivals to reduce output. The conclusions of VFJS are rather paradoxical: (1) owners with profit-maximising objectives find it convenient to conduct managers towards non-profitmaximising behaviours; (2) each owner choosing to incentivise his manager becomes a Stackelberg leader (if owners in rival firms do not delegate output decisions to managers). However, results are such that all owners act in the same way and, at equilibrium, firms end up in a prisoners' dilemma with relatively higher output and lower profits. Subsequently, in addition to the incentive contract of the original VFJS's approach, that combines own profits and sales or revenues, other kinds of managerial contracts have been studied. Specifically, Salas Fumás (1992) and Miller and Pazgal (2002) consider a scheme that accounts for the relative performance of firms by comparing firms' relative profitability. ${ }^{1}$ In that game, the manager's incentive is based on a contract including a weighted sum of firm's own profit and rival's profit (relative performance or profit delegation). Subsequently, Jansen et al. (2007) and Ritz (2008) examine the market share version of the delegation contract, i.e. a contract scheme based on a combination of firm's own profit and market share (market share delegation). Firms end up in a prisoners' dilemma also with relative profit delegation and market share delegation.

More recently, Jansen et al. (2009), Manasakis et al. (2011) and Jansen et al. (2012) compare the strategic effects of these different managerial bonus systems with homogeneous as well as heterogeneous products. Noteworthy, also with these different types of managerial incentive contracts, the essence of the traditional VFJS's result seems to be unchallenged. This means that under sales (revenue) delegation and relative profit delegation, although owners of both firms would benefit by abstaining from the use of incentives and play a normal Cournot game, they will not. Consequently, irrespective of the type of the incentive scheme, the choice of delegating is the unique SPNE of the managerial game and such a choice is Pareto inefficient.

The above-mentioned literature on delegation games typically assumes that the owner chooses the type of bonus and the relevant weight in order to maximise his own profits. Then, he makes a corresponding take-it-or-leave-it offer to the manager (Inderst, 2002). However, the dominant view of some important theoretical and empirical literature is that the manager pay-setting process is based on a certain form of bargaining played between managers and owners (or their representatives, e.g. the board of directors in large public companies).

On the one hand, financial economists consider the "arm's-length bargaining" approach as the dominant paradigm to explain the manager's pay setting (Bebchuk and Fried, 2004). This approach, in essence, assumes that pay arrangements are the product of a bargaining between executives (attempting to get the possible deal for themselves) and boards (seeking to get the best possible deal for shareholders), and constitutes the theoretical basis for the corporate law rules governing the subject. In fact, it is common that, especially in recent times, tax codes, courts' decisions and financial market rules aim at defending shareholders' interest in the bargaining between their representatives and managers over the compensation schemes. For instance, the managerial contracts' disclosure obligation - aiming principally to protect owner-shareholders against opportunistic behaviour by managers - has been introduced in several modern corporate governance codes since the early 1990s, initially in the UK and in the US and subsequently in several other

\footnotetext{
${ }^{1}$ Empirical evidence shows that both types of managers' compensations are used in actual markets (see, e.g., Jensen and Murphy, 1990; Lambert et al., 1991, for managerial schemes based on sales or revenues, and Gibbons and Murphy, 1990; Joh, 1999; Aggarwal and Samwick, 1999, for the case of relative performance.
} 
countries (as noted by van Witteloostuijn et al., 2007). In particular, in large public corporations, the pay-setting process of the "arm's-length bargaining" implies that a board of directors bargains over executive compensation arrangements. In addition, it is crucial for an effective serving of shareholders' interests that such a board is comprised of directors not being current or former employees of the firm and not affiliated with the firm other than through their directorship (i.e., really independent). Consequently, tax rules, ${ }^{2}$ court decisions ${ }^{3}$ and financial market rules ${ }^{4}$ have required exclusively independent bargainers over managers' contracts (Bebchuk and Fried, 2004). In addition, mainly due to the recent dramatic increase in managers' pay (Bebchuk and Grinstein, 2005), it has been argued that several boards may have employed compensation arrangements penalizing shareholders' interests ${ }^{5}$ and not consistent with the "arm's-length bargaining" approach. This is because of an increasing influence of the managerial "power" (Bebchuk et al., 2002; Bebchuk and Fried, 2003).

On the other hand, the existence of a bargaining over managerial contracts is also in line with the modern view of the firm arguing that, in general, "decisions by firms look more like a compromise between conflicting parties than maximization of a single objective function. Explicitly or implicitly a process of bargaining occurs continuously, and the decision that is finally taken is the result of this bargaining process." (Fershtman, 1985, p. 245). According to this view, decisions in a firm are made because of a bargaining process (Cyert and March, 1963; Aoki, 1980). Then, starting from the seminal article by Fershtman (1985) a branch of the managerial delegation literature exploring bargaining issues is emerged (the bargaining-delegation game literature, for short). In that work, Fershtman assumes that a firm chooses between profit maximisation and the adoption of a "compromise" rule with its managers, in which output decisions are made cooperatively by the owner (who maximises profits) and the manager (who maximises sales). In Fershtman (1985) as well as in the subsequent related literature, cooperative bargaining is modelled by using an axiomatic approach (Roth, 1979) and by considering the Nash solution (Nash, 1950) as the outcome of the bargaining.

Therefore, the present article attempts to capture, through a formulation of a bargaining mechanism between owners and managers, the essence of the above-mentioned different points of view on the determination of the managers' contracts. In particular, (1) the "arm's-length bargaining" approach, (2) its recent modification due to the increase in the "managerial power", and (3) firms' decision rules are viewed just like a compromise between conflicting parties.

So far, the presence of bargaining in the delegation game literature regarded exclusively wage bargaining (played between unions and managers) to question whether and how delegation affects product market competition, depending on the specifics of the managerial compensation scheme (Szymanski, 1994; Bughin, 1995; Merzoni, 2003). Later, van Witteloostuijn et al. (2007) represented the sole exception that has extended this literature by assuming that owner-shareholders negotiate with their managers about executive remuneration. Essentially, the work of van Witteloostuijn et al. (2007) differs from Fershtman (1985) since the former explicitly models out the owner-manager bargaining on the incentive parameter of the managerial contract, ${ }^{6}$ whereas in the latter work the owner-manager bargaining is on output decisions. More in detail, the model of van Witteloostuijn et al. (2007) is a two-stage delegation game in which owner-shareholders negotiate on the incentive parameter over the managerial contract (which is publicly observable)

\footnotetext{
${ }^{2}$ For instance, since 1994 in the US the federal tax code has excluded to deduct pay in excess of \$1 million annually per executive, unless either the excess compensation consists of options or it is based on the achievement of performance goals that have been established by solely independent directors.

${ }^{3}$ For instance, courts' verdicts have generally upheld compensation arrangements if bargained by independent directors.

${ }^{4}$ The Securities and Exchange Commission (SEC) of US in 2003 required for the listing that independent directors are responsible for bargaining the compensation of the CEO and other top executives.

5 This holds because, for instance, board's members have been sympathetic to managers, insufficiently motivated to bargain over compensation, or simply ineffectual in overseeing compensation (e.g. Bebchuk and Fried, 2004).

${ }^{6}$ This also holds with regard to the comparison with the works of Szymanski (1994) and Bughin (1995), who added a union-manager bargaining over wages to the Fershtman's (1985) owner-manager bargaining scheme on output.
} 
with managers in the first stage of the game. ${ }^{7}$ In the second stage, each manager engages in a Cournot competition in the product market for a homogeneous good. Under sales delegation contracts, they show that if the bargaining power of the managers increases, equilibrium profits of every firm decreases and social welfare increases. Later, in contexts of both quantity and price competition, Nakamura (2008a, 2008b) and Kamaga and Nakamura (2008) extend van Witteloostuijn et al. (2007) to the cases of differentiated goods, quadratic costs and sequential competition, respectively, to test the robustness of the main findings of van Witteloostuijn et al. (2007). While Nakamura (2008a), and Kamaga and Nakamura (2008) obtain a result similar to van Witteloostuijn et al. (2007), Nakamura (2008b) finds (unlike the three other articles) that equilibrium social welfare deteriorates in both kinds of competition in the product market if the relative bargaining power of managers is sufficiently large. ${ }^{8}$ Furthermore, Wang et al. (2008) explore the effects of owner-manager bargaining over the incentive parameter on the managerial contract on strategic trade policies, showing that the introduction of manager's bargaining leads to a decrease in the export subsidy and optimal tariff in different trade models. In the above-mentioned literature, the type of remuneration bonus is exogenous to the firm. However, recent works have developed models in which firms differ in terms of the kind of the bonus and the choice of it is an endogenous strategic decision of firms.

Thus, Jansen et al. (2009) examined the strategic consequences of the use of a set of three different managerial bonus systems (sales delegation, relative profit delegation and market share delegation) in comparison with pure profit maximisation, in duopolistic and triopolistic contexts with homogeneous products. Their main conclusions are the following: if owners can freely choose amongst these remuneration schemes, the relative performance choice turns out to be the strictly dominant one. Later, Manasakis et al. (2011) extended Jansen et al. (2009) by considering two competing firms that produce differentiated products. In their article, they argued that the dominant managerial bonus system might depend on the degree of product substitutability, ${ }^{9}$ but Jansen et al. (2012) challenge this claim, showing that the relative performance delegation is always strictly dominant for any degree of product differentiation.

However, none of them deals with the important issue of the endogenous equilibrium of the bargaining-delegation game. In this work, we fill this gap by investigating the existence of Nash equilibria ${ }^{10}$ when owners and managers bargain over executive remuneration.

The article contributes to the managerial delegation literature and investigates how the existence of a bargaining between owners and managers affects the types of contracts that firms' owners choose to compensate their managers, as well as the resulting outputs, profits and social welfare rankings. Specifically, it takes into account three different schemes according to the kind of bonus system. The bonus for the manager is proportional to: (1) profits (pure profits evaluation, PM); (2) a weighted combination of profits and sales (sales delegation, S); (3) a weighted combination of profits of the firm in which he is delegated and profits of the rival (relative profit delegation, RP). It attempts to address the following three issues. First, by starting from the literature that explicitly accounts for a bargaining owner-manager over executive remuneration (van Witteloostuijn et al., 2007), it entries in the realm of the delegation game by adding a stage in which a contract is endogenously chosen. This happens before starting on the decisions on both the bonus weight and output. To this end, we build on a game where the choice on any couple of alternative bonus

\footnotetext{
7 That is, the owner (who wants to maximise his profits) and (candidate) manager (who tries to optimise his bonus) bargain over the incentive parameter.

${ }^{8}$ This is due to the quadratic cost function, which - different from the linear cost function - causes a decrease in the producer surplus larger than the increase in the consumer surplus, as long as the relative bargaining power of managers becomes high enough.

${ }^{9}$ We note that also in Manasakis et al. (2011) the relative performance delegation is always the dominant strategy for any degree of differentiation if, as in the present article, the market share bonus is not included in the comparison.

${ }^{10}$ We do not include the "market share" incentive scheme into the analysis because, in a model with bargaining ownermanager, the resulting systems cannot be dealt with in a neat analytical form, and then explicitly solved for comparison purposes with the cases of pure profits, sales delegation and relative profit delegation.
} 
systems ( $\mathrm{S}$ versus $\mathrm{PM}, \mathrm{RP}$ versus $\mathrm{PM}, \mathrm{S}$ versus $\mathrm{RP}$ ) is investigated. ${ }^{11}$ Second, it extends the game by assuming that all the three types of bonus (PM, S and RP) might be endogenous to the firm. Third, it shows how the different managerial incentive contracts may be relevant to societal effects when the assumption that firms' owners commit over the types of contracts chosen to compensate managers is abandoned, and the choice of the bonus system is endogenous.

To address the above questions, in this work we build upon the framework of the previous literature dealing with the managerial delegation game with different alternative bonus systems (i.e., Jansen et al., 2009; Manasakis et al., 2011; Jansen et al., 2012), with one important departure. Specifically, in the spirit of the bargaining view with regard to the relationship between agents into the firm's organizational structure and by taking into account the fact that modern corporate governance codes include clauses requiring the disclosure of managerial compensation aiming to uphold shareholders' interests, we assume that the two competing firms' owners negotiate over compensation with their managers. Then, the managerial compensation contract outcomes of the bargaining process are publicly announced. In this set up, we consider a three-staged game with observable actions. In the first stage, each firm's owner commits to one type of contract to compensate his manager, which may be based only on his own profits or a linear combination of profits and either sales, or competitor's profits. As the types of contracts have become common knowledge and cannot be reset, in the second stage of the game each owner sets the weight (managerial incentive parameter) between his own profits and either his own revenues or competitor's profits. At the final stage, managers compete in quantities.

In all cases analysed, we show a noteworthy richness of equilibrium outcomes that may be different depending on whether we assume that either only two or three alternative regimes are endogenous to the firm. We also point out the dependency of endogenous equilibrium outcomes by the bargaining power of the two parties: owners and managers. Moreover, we show how the bargaining power of managers affects consumers' surplus and social welfare and give the corresponding policy implications. These findings are in sharp contrast with the previous literature, according to which only one unique equilibrium given by the choice of RP exists and the established ranking of the welfare for firms, consumers and society as a whole are with respect to the different bonus systems.

A relevant consequence of our results is to question the wisdom of the previous managerial delegation literature, which assumes that firms' owners delegate output decisions to managers and/or, more specifically, they should choose a relative performance bonus system. Owners may actually choose to do not delegate or designing sales delegation contracts.

The rest of the article proceeds as follows. Section 2 introduces a bargaining process between owners and managers over the manager's bonus in a duopoly with quantity-setting firms. Sections 3,4 and 5 study the game between any couple of alternative bonus systems. Section 6 takes into account all the three of bonus systems and looks at the emergence of Nash equilibria in pure and mixed strategies in such a case. Section 7 develops a welfare analysis. Section 8 outlines the conclusions.

\section{The bargaining-delegation game}

We assume an economy with two types of agents: firms and consumers. The economy is bisectorial, i.e. there exist a competitive sector that produces the numeraire good $y$, and a duopolistic sector with firm 1 and firm 2 that produce differentiated products. Let $p \geq 0$ and $q_{i} \geq 0$ denote the market price and quantity produced by firm $i$, respectively $(i=1,2)$.

\footnotetext{
11 This corresponds to the case in which only one or two bonus systems are available to the firm because of, for instance, country-specific norms and rules.
} 
There exists a continuum of identical consumers which have preferences towards $q_{1}, q_{2}$ and $y$ represented by a separable utility function $V\left(q_{1}, q_{2}, y\right): \mathfrak{R}_{+}^{3} \rightarrow \mathfrak{R}_{+}$, which is linear in the numeraire good. The representative consumer maximises $V\left(q_{1}, q_{2}, y\right)=U\left(q_{1}, q_{2}\right)+y$ with respect to quantities subject to the budget constraint $p Q+y=M$, where $U\left(q_{1}, q_{2}\right): \mathfrak{R}_{+}^{2} \rightarrow \mathfrak{R}_{+}$is a twice continuously differentiable function, $Q=q_{1}+q_{2}$ is total supply and $M$ denotes the consumer's exogenous nominal income. This income is high enough to avoid the existence of corner solutions. Since $V\left(q_{1}, q_{2}, y\right)$ is a separable function and it is linear in $y$, there are no income effects on the duopolistic sector. This implies that for a large enough level of income, the representative consumer's optimisation problem can be reduced to choose $q_{i}$ to maximise $U(Q)-p Q+M$. Utility maximisation, therefore, yields the inverse demand functions (i.e., the price of good $i$ as a function of quantities): $p=\frac{\partial U}{\partial q_{i}}=P_{i}\left(q_{i}, q_{j}\right)$, for $q_{i}>0$ and $i=1,2, i \neq j$.

To proceed further with the analysis, we assume explicit demand functions. To this end, we take into account the usual specification of quadratic utility functions as proposed by Dixit (1979) and subsequently used, amongst others, by Singh and Vives (1984), Häckner (2000), and Correa-López and Naylor (2004). The important feature of the quadratic utility function is that it generates a system of linear demand functions. Therefore, we assume that preferences of the representative consumer over $q_{1}$ and $q_{2}$ are captured by:

$$
U\left(q_{1}, q_{2}\right)=q_{1}+q_{2}-\frac{1}{2}\left(q_{1}^{2}+q_{2}^{2}+2 q_{1} q_{2}\right) .
$$

The representative consumer maximises (1) with respect to $q_{1}$ and $q_{2}$ subject to the budget constraint. Then, the linear inverse market demand is given by:

$$
p=1-Q \text {. }
$$

By following Correa-López and Naylor (2004), we assume that firm $i$ produces with a constant (marginal) returns to labour production function, that is $q_{i}=L_{i}$, where $L_{i}$ represents the labour force employed by firm $i$. Firms face the same (constant) average and marginal cost $0 \leq w<1$ for every unit of output produced. Therefore, firm $i$ 's cost function is linear and described by:

$$
C_{i}\left(q_{i}\right)=w L_{i}=w q_{i} .
$$

Profits of firm $i\left(\Pi_{i}\right)$ can be written as follows:

$$
\Pi_{i}=(p-w) q_{i}
$$

From now on, we fix $w=0$ without loss of generality. Then, profits boils down to $\Pi_{i}=p q_{i}$.

As is usual in the managerial delegation literature since the works of VFJS, we assume that the existence of interactions between owners and managers influences market behaviours in a competitive (duopoly) economy. In particular, in corporate firms where ownership and control are separate, managers have to make decision in the product market with quantity competition or price competition, and owners direct them by using specific compensation schemes. In the words of Jansen et al. (2009, p. 142), "the managerial incentive contract can be manipulated by owners in a principal-agent context such that the owners' interests are served by their managers". These models are usually built on as two-stage games: stage 1 (the contract stage) and stage 2 (the market stage). In the former one, each owner maximises his profits by choosing the weight of the bonus in the managerial contract. In the latter, each manager knows the weights chosen in the previous stage and plays a game in the product market by choosing quantity (in a Cournot competition set up) or price (in a Bertrand competition set up) in order to maximise his utility. Knowing that each owner and each manager acts simultaneously and independent from the rivals, these games are solved by invoking the backward induction argument. We will use this solution method later in this article. 
Different from the existing literature, we follow van Witteloostuijn et al. (2007) and assume the existence of a bargaining process between owners and managers over the weight of executive remuneration. In line with van Witteloostuijn et al. (2007), will refer at this stage as the bargaining stage instead of the standard contract stage. We also add a third stage where players choose the nature of the bonus. This happens before starting on the decisions on both the bonus weight and output. Specifically, we build on a game where the choice on any couple of alternative bonus systems ( $\mathrm{S}$ versus PM, RP versus PM, S versus RP) is investigated. Second, we extend the game by assuming that all the three types of bonus (PM, S and RP) might be endogenous to the firm.

To sum up, the timing of our bargaining-delegation game is definitely the following. At stage 1, players choose the nature of the bonus (the contract-bonus stage) by comparing either each couple of alternatives (i.e., S versus PM, RP versus PM and S versus RP) or the three alternatives together. At stage 2, players are engaged in a bargaining process to choose executive remuneration (the bargaining stage). At stage 3, players choose the quantity in the product market (the market stage).

\subsection{Sales delegation $(S)$}

With sales delegation contracts (Vickers 1985), the owner of each firm hires a manager and delegates the output decision to him. Each manager receives a fixed salary and a bonus related to a weighted combination of firm's profits and sales. Manager $i$ 's remuneration, therefore, can be expressed as $\omega_{i}=\mathrm{A}_{i}+\mathrm{B}_{i} u_{i} \geq 0$, where $\mathrm{A}_{i} \geq 0$ is the fixed salary component in manager's compensation, $\mathrm{B}_{i} \geq 0$ is a constant and $u_{i}$ is the utility of manager $i$. Without loss of generality, we set the fixed salary component of executive compensation to zero throughout the article. Mathematically, utility of manager $i$ takes the following form:

$$
u_{i}=\Pi_{i}+b_{i} q_{i},
$$

where $b_{i}$ is the incentive parameter chosen by both the owner and manager of $i$ th firm in the bargaining stage. It may be positive or negative depending on whether the owner provides incentives or disincentives to the manager. If $b_{i}>0$ (resp. $b_{i}<0$ ), an increase in the modulus of $b_{i}$ implies that the manager becomes more (resp. less) aggressive in the market. Of course (5) holds when profits of firm $i$ are positive. If profits are negative, managers have no bonus.

\subsection{Relative profit delegation $(R P)$}

With relative profit delegation (Miller and Pazgal, 2002), utility of manager $i$ is a weighted combination between firm $i$ 's profits and rival's (firm $j$ ) profits, that is:

$$
u_{i}=\Pi_{i}-b_{i} \Pi_{j}
$$

$i=1,2, i \neq j$, where $-1<b_{i}<1$. In other words, according to (6) the utility of manager $i$ depends on firm $i$ 's relative profitability. In this case, negative (resp. positive) values of $b_{i}$ imply that the owner of $i$ th firm is interested in manager's cooperation (resp. competition) with the manager hired in the rival's firm. In the case of pure profit evaluation, $b_{i}=0$ and $u_{i}=\Pi_{i}$.

\subsection{The bargaining owner-manager}

We assume that the weight of the bonus of players $i\left(b_{i}\right)$ in the managerial contract is chosen in the second stage of the game by both owners and managers in a bargaining process that weights manager's utility and owners' profits (instead of being chosen unilaterally by the owner by means of profit maximisation). Since owners and managers have conflicting interest, "it makes sense for 
them to bargain over the weight $\left[b_{i}\right]$ "' (van Witteloostuijn, 2007, p. 899). Then, player $i$ maximises the following Nash product by choosing $b_{i}$ :

$$
\mathrm{N}_{i}=u_{i}^{k} \Pi_{i}^{1-k}
$$

where $0 \leq k<1$ is the relative bargaining power of manager hired in firm $i$. When $k=0$, (7) boils down to the standard case in which only the owner is involved in determining the weight of the bonus in the managerial contract. Of course, if firms do not hire a manager $\left(b_{i}=0\right)$ their objective becomes standard pure profit maximisation and the manager behaves just like a profit-maximiser in such a case. Therefore, when $k=0$ by using market demand (2) we get the following usual reaction functions for firm 1 and firm 2, that is:

$$
\frac{\partial \Pi_{1}}{\partial q_{1}}=0 \Leftrightarrow q_{1}\left(q_{2}\right)=\frac{1-q_{2}}{2},
$$

and

$$
\frac{\partial \Pi_{2}}{\partial q_{2}}=0 \Leftrightarrow q_{2}\left(q_{1}\right)=\frac{1-q_{1}}{2} .
$$

Then, from (8) and (9) we find that equilibrium values of quantity, market price and profit of each firm when the contract is pure profit maximisation (PM) are respectively given by

$$
q_{i}^{P M / P M}=1 / 3, \quad p^{P M / P M}=1 / 3 \text { and } \Pi_{i}^{P M / P M}=1 / 9 .
$$

\section{Sales delegation versus profit maximisation}

In this section, we study sales delegation versus profit maximisation by taking into account the bargaining owner-manager discussed in Section 2.3, and adding a third stage to the standard twostage game of Jansen et al. (2009), in which players choose the nature of the bonus. In other words, we will look at whether players should delegate or not when $k \neq 0$ in a Cournot duopoly with homogeneous product.

\subsection{The model with sales delegation}

By assuming now that the owner of each firm hires a manager and delegates output decisions to him under sales delegation, the backward logic argument allows us to proceed as follows. Given decisions taken in both the contract-bonus stage and bargaining stage, in the market stage the manager of each firm maximises utility (5) with respect to quantity. Therefore, the reaction functions of managers of firm 1 and firm 2 (as a function of rival's quantity and his how bonus) are given by:

$$
\frac{\partial u_{1}}{\partial q_{1}}=0 \Leftrightarrow q_{1}\left(q_{2}, b_{1}\right)=\frac{1-q_{2}+b_{1}}{2}
$$

and

$$
\frac{\partial u_{2}}{\partial q_{2}}=0 \Leftrightarrow q_{2}\left(q_{1}, b_{2}\right)=\frac{1-q_{1}+b_{2}}{2} .
$$

The reaction functions clearly show that if weight $b_{i}$ is positive (resp. negative), manager $i$ has an incentive to increase (resp. reduce) output. From (11) and (12), we definitely get quantities as function of both weights, that is:

$$
\bar{q}_{1}\left(b_{1}, b_{2}\right)=\frac{1+2 b_{1}-b_{2}}{3}
$$

and

$$
\bar{q}_{2}\left(b_{1}, b_{2}\right)=\frac{1+2 b_{2}-b_{1}}{3} .
$$


In the bargaining stage, owner and manager of firm $i$ use (13) and (14) and maximises the Nash product (7) with respect to $b_{i}$ (given $b_{j}$ ). Therefore, the system of reaction functions in the bonus space are the following:

$$
\frac{\partial \mathrm{N}_{1}}{\partial b_{1}}=0 \Leftrightarrow b_{1}\left(b_{2}\right)=\frac{\left(1-b_{2}\right)(1+3 k)}{4},
$$

and

$$
\frac{\partial \mathrm{N}_{2}}{\partial b_{2}}=0 \Leftrightarrow b_{2}\left(b_{1}\right)=\frac{\left(1-b_{1}\right)(1+3 k)}{4} .
$$

Ceteris paribus, an increase in $k$ (the relative bargaining power of the manager) increases $b_{i}$. By using (15) and (16), we definitely obtain the (symmetric) equilibrium value of the bonus bargained by owner and manager (with sales delegation) within every firm, that is:

$$
b_{i}^{S / S}=\frac{1+3 k}{5+3 k} \text {. }
$$

From (17) the following proposition holds.

Proposition 1. Under sales delegation, $0<b_{i}^{S / S}<1$ for any $0 \leq k<1$. In addition, $b_{i}^{S / S}$ is an increasing function of $k$.

Proof. The proof is obvious from (17). Q.E.D.

It is clear that the higher the weight of the manager in the Nash bargaining, the higher the incentive parameter $b$ in the managerial contract.

Given (17), equilibrium values of quantity, market price, firm's profit and manager's utility under sales delegation $(\mathrm{S})$ are respectively given by

$$
q_{i}^{S / S}=\frac{2(1+k)}{5+3 k}, \quad p^{S / S}=\frac{1-k}{5+3 k}, \quad \Pi_{i}^{S / S}=\frac{2(1-k)(1+k)}{(5+3 k)^{2}} \quad \text { and } \quad u_{i}^{S / S}=\frac{4(1+k)^{2}}{(5+3 k)^{2}} .
$$

Straightforward calculations from (18) show that an increase in $k$ induces a monotonic increase (resp. decrease) in the quantity produced by (resp. in the profits of) both delegated firms, while decreasing (resp. increasing) the market price (resp. the utility of managers) monotonically. In addition, quantities (resp. profits) under (S,S) are always higher (resp. lower) than quantities (resp. profits) under (PM,PM). It may also be of interest to ascertain the reasons why the outcome of an increase in $k$ on profits of firm $i$ is negative. This is given by the total derivative of $\Pi_{i}^{S / S}$ with respect to $k$. Let

$$
\Pi_{i}^{S / S}=\Pi_{i}^{S / S}\left\{p\left[q_{i}\left(b_{i}(k), b_{j}(k)\right), q_{j}\left(b_{i}(k), b_{j}(k)\right)\right], q_{i}\left(b_{i}(k), b_{j}(k)\right)\right\},
$$

$i=1,2, i \neq j$ be the generic profit function of firm $i$. Its total derivative with respect to $k$ gives:

$$
\frac{d \Pi_{i}^{S / S}}{d k}=\overbrace{\frac{\partial \Pi_{i}^{S / S}}{\partial p}}^{+} \cdot[\overbrace{\frac{\partial p}{\partial q_{i}}}^{-} \cdot(\overbrace{\frac{\partial q_{i}}{\partial b_{i}}}^{+} \cdot \overbrace{\frac{\partial b_{i}}{\partial k}}^{+}+\overbrace{\frac{\partial q_{i}}{\partial b_{j}}}^{-} \cdot \frac{\partial b_{j}}{\partial k})+\overbrace{\frac{\partial p}{\partial q_{j}}}^{+} \cdot(\overbrace{\frac{\partial q_{j}}{\partial b_{i}}}^{-} \cdot \overbrace{\frac{\partial b_{i}}{\partial k}}^{+}+\overbrace{\frac{\partial q_{j}}{\partial b_{j}}}^{+} \cdot \overbrace{\frac{\partial b_{j}}{\partial k}}^{+})]+\overbrace{\frac{\partial \Pi_{i}^{S / S}}{\partial q_{i}}}^{+} \cdot(\overbrace{\frac{\partial q_{i}}{\partial b_{i}}}^{+} \cdot \overbrace{\frac{\partial b_{i}}{\partial k}}^{+}+\overbrace{\frac{\partial q_{i}}{\partial b_{j}}}^{-} \cdot \frac{\partial_{b_{j}}^{+}}{\partial k}) \cdot
$$

From this derivative, it is clear that the relative bargaining power of the manager affects profits of $i$ th firm through two channels: a direct effect that passes through the quantity produced by that firm, and an indirect effect via the change in market price. With regard to the former effect, an increase in $k$ causes an increase in the incentive parameter for player $i$ and player $j$. The increase in $b_{i}$ (resp. $b_{j}$ ) tends to increase (resp. reduce) the quantity produced by firm $i$. Nevertheless, the net effect of an increase in $k$ on $q_{i}$ is positive, that is the positive effect of the increased incentive parameter of the quantity produced by $i$ th firm dominates the negative effect that passes through 
the reduced production of the rival. Then, $k$ increases, $q_{i}$ increase and $\Pi_{i}^{S / S}$ goes up through this channel. With regard to the latter effect (the indirect negative effect of $k$ on the market price), we have the following. Since an increase in $k$ positively affects both $b_{i}$ and $b_{j}$, and the net effect on quantities produced by firm $i$ and firm $j$ is positive, then the increased production reduces the marginal willingness to pay of consumers, so that the market price goes down and $\Pi_{i}^{S / S}$ declines through this channel. Definitely, the percentage reduction in market price that comes from the increase in $k$ is larger than the percentage increase in total supply, so that profits of both sales delegated firms monotonically reduce when the relative power of managers in the Nash bargaining increases.

\subsection{The model with mixed behaviours}

In this section we assume that firm 1 hires a manager with a sales delegation contract $\left(b_{1} \neq 0\right)$ and firm 2 is profit maximising ( $\left.b_{2}=0\right)$. Then, at the market stage, firm 1 maximises (5) with respect to $q_{1}$, and firm 2 maximises (4) with respect to $q_{2}$. Therefore, the reaction functions of manager of firm 1 and owner of firm 2 are given by:

$$
\frac{\partial u_{1}}{\partial q_{1}}=0 \Leftrightarrow q_{1}\left(q_{2}, b_{1}\right)=\frac{1-q_{2}+b_{1}}{2},
$$

and

$$
\frac{\partial \Pi_{2}}{\partial q_{2}}=0 \Leftrightarrow q_{2}\left(q_{1}\right)=\frac{1-q_{1}}{2}
$$

From (19) and (20), we get

$$
\bar{q}_{1}\left(b_{1}\right)=\frac{1+2 b_{1}}{3}
$$

and

$$
\bar{q}_{2}\left(b_{1}\right)=\frac{1-b_{1}}{3} .
$$

As expected, an increase in $b_{1}$ increases the quantity produced where the manager is delegated and reduces the quantity produced by the rival. We note that the increase in quantity induced by a rise in $b_{1}$ when only firm 1 is delegated, is higher than the increase in quantity due to an increase in $b_{1}$ when both firms are delegated. This because in this latter case there exists a negative effect on quantity due to the presence of weight $b_{1}$ of the manager hired in the rival firm.

Since $b_{2}=0$, in the bargaining stage only the owner and the manager of firm 1 are engaged in a Nash bargaining and then maximise (7) with respect to $b_{1}$. Therefore,

$$
\frac{\partial \mathrm{N}_{1}}{\partial b_{1}}=0 \Leftrightarrow b_{1}=\frac{1+3 k}{4}
$$

Then, the (asymmetric) equilibrium values of the bonus of player $1(\mathrm{~S})$ and player $2(\mathrm{PM})$ are

$$
b_{1}^{S / P M}=\frac{1+3 k}{4}, \quad b_{2}^{S / P M}=0 .
$$

Also in this asymmetric case, we have that $0<b_{1}^{S / P M}<1$ and $b_{1}^{S / P M}$ is an increasing function of $k$. Given Eq. (24), equilibrium values of quantity, market price, profit of sales delegated firm 1 and firm 2 (that does not hire any manager) and manager 1's utility are given by

$$
q_{1}^{S / P M}=\frac{1+k}{2}, \quad q_{2}^{S / P M}=\frac{1-k}{4}, \quad p^{S / P M}=\frac{1-k}{4},
$$

and 


$$
\Pi_{1}^{S / P M}=\frac{(1-k)(1+k)}{8}, \quad \Pi_{2}^{S / P M}=\frac{(1-k)^{2}}{16} \quad \text { and } \quad u_{1}^{S / P M}=\frac{(1+k)^{2}}{4} .
$$

From (25.1) and (25.2), it is easy to see that the managerial firm produces more and its profits are always higher than the profit-maximising rival does. This because the weight $k$ acts as an incentive for the manager of the delegated firm to produce more than the rival but the market price paid by consumers is the same for products of both firms (we recall that products 1 and 2 are homogeneous). A rise in $k$ increases (resp. reduces) the quantity produced by the delegated (resp. profit maximising) firm, whereas the effect of an increase in the relative bargaining power of manager on profits is clearly decreasing for both firms and increasing for the utility of manager 1 .

As for the case in which both firms are delegated, we now look at the reason why the outcome of an increase in $k$ on $\Pi_{1}^{S / P M}$ and $\Pi_{2}^{S / P M}$ is negative. Define the generic profit function of firm 1 (S) and firms $2(\mathrm{PM})$ as follows:

and

$$
\Pi_{1}^{S / P M}=\Pi_{1}^{S / P M}\left\{p\left[q_{1}\left(b_{1}(k)\right), q_{2}\left(b_{1}(k)\right)\right], q_{1}\left(b_{1}(k)\right)\right\},
$$

$$
\Pi_{2}^{S / P M}=\Pi_{2}^{S / P M}\left\{p\left[q_{1}\left(b_{1}(k)\right), q_{2}\left(b_{1}(k)\right)\right], q_{2}\left(b_{1}(k)\right)\right\},
$$

Total differentiation of these two functions with respect to $k$ gives:

$$
\frac{d \Pi_{1}^{S / P M}}{d k}=\overbrace{\frac{\partial \Pi_{1}^{S / P M}}{\partial p}}^{+} \cdot(\overbrace{\frac{\partial p}{\partial q_{1}}}^{-} \cdot \overbrace{\frac{\partial q_{1}}{\partial b_{1}}}^{+} \cdot \overbrace{\frac{d b_{1}}{d k}}^{+}+\overbrace{\frac{\partial p}{\partial q_{2}}}^{-} \cdot \overbrace{\frac{\partial q_{2}}{\partial b_{1}}}^{-} \cdot \overbrace{\frac{d b_{1}}{d k}}^{+})+\overbrace{\frac{\partial \Pi_{1}^{S / P M}}{\partial q_{1}}}^{+} \cdot \overbrace{\frac{\partial q_{1}}{\partial b_{1}}}^{+} \cdot \overbrace{\frac{d b_{1}}{d k}}^{+},
$$

and

$$
\frac{d \Pi_{2}^{S / P M}}{d k}=\overbrace{\frac{\partial \Pi_{2}^{S / P M}}{\partial p}}^{+} \cdot(\overbrace{\frac{\partial p}{\partial q_{1}}}^{=} \cdot \overbrace{\frac{\partial q_{1}}{\partial b_{1}}}^{+} \cdot \overbrace{\frac{d b_{1}}{d k}}^{+}+\overbrace{\frac{\partial p}{\partial q_{2}}}^{-} \cdot \overbrace{\frac{\partial q_{2}}{\partial b_{1}}}^{-} \cdot \overbrace{\frac{d b_{1}}{d k}}^{+})+\overbrace{\frac{\partial \Pi_{2}^{S / P M}}{\partial q_{2}}}^{+} \cdot \overbrace{\frac{\partial q_{2}}{\partial b_{1}}}^{-} \overbrace{\frac{d b_{1}}{d k}}^{+} .
$$

With regard to the effects on an increase in $k$ on profits of the sales delegated firm, as usual they pass through two distinct channels: a direct effect on quantity and an indirect effect on market price. In fact, a rise in $k$ positively affect the incentive parameter that in turn induces manager hired in firm 1 to increase his how production, so that profits increases through this (direct) channel. In addition, the increase in $k$ that tends to increase $b_{1}$ negatively acts on production of the profit maximising firm 2. This actually causes an increase in market price and then in profits of firm 1. However, the increase in $b_{1}$ produces a substantial increase in $q_{1}$ and this, in turn, implies a strong reduction in market price that definitely causes a reduction in profits of the delegated firm.

With regard to profit maximising firm 2, we have that an increase in $k$ induces the same depressing indirect effects on profits (as those detailed above) due to the reduction in the marginal willingness to pay of consumers caused by the increase in $q_{1}$. This negative effect is strengthened by a further negative (direct) force induced by a lower production of firm 2 due to the increase in $b_{1}$. Definitely, profits of the profit maximising firm 2 monotonically reduces as $k$ increases.

\subsection{The contract-bonus stage with $S$ and $P M$}

We now add a third stage where players choose the nature of the bonus. To do this, we let firms play a game by comparing payoffs (profits) under S and PM. Table 1 shows the payoff matrix that summarises the outcomes of S versus PM. 
Table 1. Payoff matrix: profits with sales delegation (S) and profit maximisation (PM).

\begin{tabular}{|c|c|c|}
\hline Firm 2 & PM & S \\
\hline Firm 1 & $\frac{1}{9}, \frac{1}{9}$ & $\frac{(1-k)^{2}}{16}, \frac{(1-k)(1+k)}{8}$ \\
\hline S & $\frac{(1-k)(1+k)}{8}, \frac{(1-k)^{2}}{16}$ & $\frac{2(1-k)(1+k)}{(5+3 k)^{2}}, \frac{2(1-k)(1+k)}{(5+3 k)^{2}}$ \\
\hline
\end{tabular}

Then, the following lemma and proposition hold.

Lemma 1. $\Pi_{i}^{P M / P M}>\Pi_{i}^{S / S}$ for any $0 \leq k<1$.

Proposition 2. [S versus PM]. (1) If $0 \leq k<1 / 3$ then there exists a unique SPNE, that is (S,S), and it is Pareto inefficient, so that a standard prisoner's dilemma emerges. ${ }^{12}$ (2) If $1 / 3<k<1$ then there exist two pure-strategy Nash equilibria, that is (S,S) and (PM,PM), and the game becomes a coordination game. In addition, $(\mathrm{PM}, \mathrm{PM})$ payoff-dominates $(\mathrm{S}, \mathrm{S})$.

Proof. Profit differentials are the following:

and

$$
\begin{gathered}
\Delta_{1}=\Pi_{1}^{S / P M}-\Pi_{1}^{P M / P M}=\frac{(1+3 k)(1-3 k)}{72}, \\
\Delta_{2}=\Pi_{1}^{P M / S}-\Pi_{1}^{S / S}=\frac{(1+3 k)\left(3 k^{3}+3 k^{2}+k-7\right)}{16(3 k+5)^{2}}<0,
\end{gathered}
$$

$$
\Delta_{3}=\Pi_{1}^{P M / P M}-\Pi_{1}^{S / S}=\frac{(7+9 k)(1+3 k)}{9(3 k+5)^{2}}>0 .
$$

The sign of $\Delta_{1}$ changes depending on the size of the bargaining power $k$. In particular, if $0 \leq k<1 / 3$ then $\Delta_{1}>0, \Delta_{2}<0$ and $\Delta_{3}>0$, whereas when $1 / 3<k<1$ then $\Delta_{1}<0, \Delta_{2}<0$ and $\Delta_{3}>0$. Then, the proposition follows from Lemma 1 and these arguments. Q.E.D.

Proposition 2 shows that there may exist multiple equilibria in pure strategies when owners and managers are engaged in a bargaining over executive remuneration, and managers' bargaining power is sufficiently large. Managers want to maximise their own objective $\left(u_{i}\right)$. In doing this, they tend to increase production when their relative bargaining strength increases. Indeed, when $k$ is sufficiently small $(0 \leq k<1 / 3)$, owners' profits weight relatively more than managers' utility in the Nash product, and the final outcome of the contract-bonus stage is the standard result of VFJS, so that both firms hire a manager and delegate output decisions to him (S strictly dominates PM), but this Nash equilibrium is sub-optimal (prisoner's dilemma). This because there exists an incentive for both players to coordinate towards profit maximisation that gives higher payoffs, but there do not exist a unilateral incentive to deviate from $\mathrm{S}$ (i.e., there exists a unilateral incentive to deviate from PM). However, when $k$ becomes larger $(1 / 3<k<1)$, PM is no more strictly dominated by $\mathrm{S}$ because profit of the firm that plays $\mathrm{S}$ when the other plays PM is reducing when $k$ is increasing. In particular, this profit becomes lower than the corresponding outcome when both firms play PM. The consequence is that there is no more a unilateral incentive for each player to deviate from PM. The economic intuition behind the change in the sign of $\Delta_{1}$ is the following: since $\Pi_{1}^{P M / P M}$ does not depend on $k$, an increase in the relative bargaining power of the manager causes an increase in the incentive parameter $b_{1}$ that, in turn, causes an increase in $q_{1}$. However, the increase in $\Pi_{1}^{S / P M}$ that

${ }^{12}$ We do not explicitly account for the case $k=1 / 3$ as well as the threshold cases that we will encounter later in this article. 
comes from the increased production of the managerial firm is more than compensated by the reduction in profits due to a reduced marginal willingness to pay of consumers. Therefore, when $1 / 3<k<1$ from a prisoner's dilemma the game becomes a coordination game, and there exist multiple equilibria in pure strategies.

Then, it may be useful to adopt a criterion to select equilibria. To this purpose, we introduce mixed strategies and show that a (unique) mixed-strategy Nash equilibrium does actually exist. To proceed further, we consider that a Nash equilibrium in mixed strategies can be obtained by defining probabilities $x_{1}$ and $1-x_{1}$ (resp. $x_{2}$ and $1-x_{2}$ ) that firm 1 (resp. firm 2) plays either S or PM. Therefore, we find that a mixed-strategy Nash equilibrium is given by:

$$
x_{i}=x_{*}^{S / P M}=\frac{\Pi_{i}^{S / P M}-\Pi_{i}^{P M / P M}}{\left(\Pi_{i}^{S / P M}-\Pi_{i}^{P M / P M}\right)+\left(\Pi_{i}^{P M / S}-\Pi_{i}^{S / S}\right)}=\frac{2(5+3 k)^{2}(3 k-1)}{(1+3 k)^{2}(13+3 k)} .
$$

where $i=1,2$. From (26) it is easy to check that $x_{*}^{S / P M}>0$ only when $k>1 / 3$ and it is an increasing function of $k$. This probability vanishes when $k=1 / 3$ and approaches 1 when $k \rightarrow 1$. This behaviour is in line with the results summarised in Proposition 2. In fact, for $k<1 / 3$ there exists only one (sub-optimal) Nash equilibrium and the game boils down to the standard prisoner's dilemma detailed by VFJS.

The rule that comes from the mixed-strategy Nash equilibrium (26) is the following: each firm will choose to play S (resp. PM) as a pure strategy if the rival plays S (resp. PM) with a probability $x>x_{*}^{S / P M}$ (resp. $x<x_{*}^{S / P M}$ ). The higher $k$, the higher the probability of playing PM as a pure strategy. It is important to recall that for a parameter configuration supporting multiple equilibria in pure strategy, the analysis can be refined. In particular, by resorting to well-known criteria of Pareto-dominance and Risk-dominance it is possible to select Nash equilibria. ${ }^{13}$ However, for the sake of simplicity, we limit ourselves to point out whether and how Pareto-dominance appears. This because such a criterion is immediately observable by direct comparison of profits. In fact, when $1 / 3<k<1$ the Pareto dominance criterion allows us to conclude that (PM,PM) Pareto dominates $(\mathrm{S}, \mathrm{S})$. Table 2 summarises the main findings of the two-strategy game $\mathrm{S}$ versus PM when $k$ varies.

Table 2. Summary of the main results of S versus PM.

\begin{tabular}{|c|c|c|}
\hline Efficiency & $\Pi_{i}^{P M / P M}>\Pi_{i}^{S / S}$ & $\Pi_{i}^{P M / P M}>\Pi_{i}^{S / S}$ \\
\hline $\mathrm{NE}$ & $(\mathrm{S}, \mathrm{S})$ & $(\mathrm{S}, \mathrm{S})$ and $(\mathrm{PM}, \mathrm{PM})$ \\
\hline$k$ & $0 \leq k<1 / 3$ & $1 / 3<k<1$ \\
\hline
\end{tabular}

\section{Relative profit delegation versus profit maximisation}

Different from Section 3, we now compare relative profit versus profit maximisation in a bargaining owner-manager set up and then look at whether players should delegate or not in this context.

\subsection{The model with relative profit delegation}

By assuming now that the owner of each firm hires a manager and delegates output decisions to him under relative profit delegation. As usual, we start by taking as given players' decisions in both the contract-bonus stage and bargaining stage. Then, in the market stage manager $i$ chooses quantity by maximising utility given by Eq. (6). Therefore, the reaction function of managers of firm 1 and firm 2 (as a function of rival's quantity and his how bonus) are given by:

$$
\frac{\partial u_{1}}{\partial q_{1}}=0 \Leftrightarrow q_{1}\left(q_{2}, b_{1}\right)=\frac{1-q_{2}\left(1-b_{1}\right)}{2},
$$

and

\footnotetext{
${ }^{13}$ A Nash equilibrium is said to be Payoff-dominant if it is Pareto superior to all other Nash equilibria in the game and Risk-dominant if it is less risky.
} 


$$
\frac{\partial u_{2}}{\partial q_{2}}=0 \Leftrightarrow q_{2}\left(q_{1}, b_{2}\right)=\frac{1-q_{1}\left(1-b_{2}\right)}{2} .
$$

As in the case with sales delegation, if weight $b_{i}$ is positive (resp. negative), manager $i$ has an incentive to increase (resp. reduce) output. Different from the previous case, however, weight $b_{i}$ enters multiplicatively with respect to quantity $q_{j}$. Eqs. (27) and (28) allow us to get:

$$
\bar{q}_{1}\left(b_{1}, b_{2}\right)=\frac{1+b_{1}}{3+b_{1}\left(1-b_{2}\right)+b_{2}},
$$

and

$$
\bar{q}_{2}\left(b_{1}, b_{2}\right)=\frac{1+b_{2}}{3+b_{1}\left(1-b_{2}\right)+b_{2}} .
$$

Eqs. (29) and (30) are used in the bargaining stage by the owner and the manager of every firm to maximise (7) with respect to the corresponding weight. Then, we get $\partial \mathrm{N}_{1} / \partial b_{1}=0$ and $\partial \mathrm{N}_{2} / \partial b_{2}=0$. By following van Witteloostuijn et al. (2007), we introduce the assumption of symmetry of managers' types by assuming that $b_{1}=b_{2}=b$. Then,

$$
\frac{\partial \mathrm{N}_{i}}{\partial b_{i}}=0 \Leftrightarrow \frac{2\left(1-b_{i}^{2}\right)^{k}\left(1+b_{i}\right)^{1-k}\left[1-3 k-b_{i}(3-k)\right]}{3-b_{i}}=0 .
$$

The symmetric equilibrium value of weight $b$ when both firms use relative profit delegation contracts is therefore given by:

$$
b_{i}^{R P / R P}=\frac{1-3 k}{3-k} .
$$

From (32) we may state the following proposition:

Proposition 3. Under relative profit delegation, $0<b_{i}^{R P / R P} \leq 1 / 3$ (resp. $-1<b_{i}^{R P / R P}<0$ ) when $0 \leq k<1 / 3$ (resp. $1 / 3<k<1$ ). In addition, $b_{i}^{R P / R P}$ is a decreasing function of $k$.

Proof. The proof is obvious from (32). Q.E.D.

Given the optimal value of the bonus stated in (32), it is clear that the owner of every firm wants that his own manager competes (resp. colludes) with the rival when the relative power of the latter in the Nash bargaining is small (resp. large) enough. The reason why we got this finding will be clear later in this article when we will discuss how $k$ affects profits and manager's utility.

By using (32) together with (2), (4), (29) and (30), we get the (symmetric) equilibrium values of quantity, market price, profit of each firm and manager's utility under relative profit delegation, that is:

$$
q_{i}^{R P / R P}=\frac{3-k}{8}, \quad p^{R P / R P}=\frac{1+k}{4}, \quad \Pi_{i}^{R P / R P}=\frac{(3-k)(1+k)}{32} \quad \text { and } \quad u_{i}^{R P / R P}=\frac{(1+k)^{2}}{16}
$$

From (33) it is clear that an increase in $k$ monotonically increases (resp. decrease) equilibrium values of market price, profits and manager's utility (resp. quantity). In addition, the following proposition holds.

Proposition 4. If $0 \leq k<1 / 3$ (resp. $1 / 3<k<1$ ) then $q_{i}^{R P / R P}>q_{i}^{P M / P M}$ (resp. $q_{i}^{R P / R P}<q_{i}^{P M / P M}$ ) and $\Pi_{i}^{R P / R P}<\Pi_{i}^{P M / P M}$ (resp. $\Pi_{i}^{R P / R P}>\Pi_{i}^{P M / P M}$ ).

Proof. The proof is obvious by comparing quantities and profits in (10) and (33). Q.E.D. 
It may also be of interest to ascertain the reasons why the outcome of an increase in $k$ on the equilibrium value of profits of both firms is positive under relative profit delegation. This will be useful later in the contract-bonus stage when we will look at the economic reasons why profit differentials change. Then, let the generic profit function of firm $i$ be:

$$
\Pi_{i}^{R P / R P}=\Pi_{i}^{R P / R P}\left\{p\left[q_{i}\left(b_{i}(k), b_{j}(k)\right), q_{j}\left(b_{i}(k), b_{j}(k)\right)\right], q_{i}\left(b_{i}(k), b_{j}(k)\right)\right\},
$$

where $i=1,2, i \neq j$. Its total derivative with respect to $k$ gives:

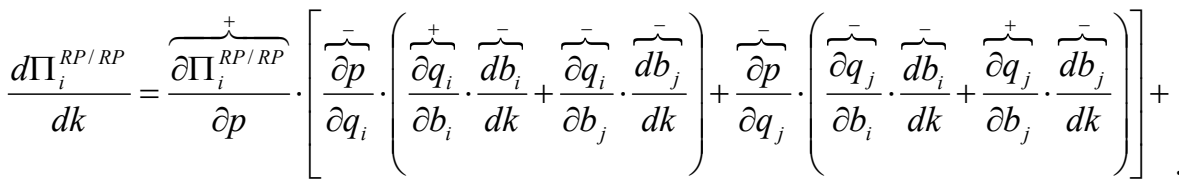

$$
\begin{aligned}
& +\overbrace{\frac{\partial \Pi_{i}^{R P / R P}}{\partial q_{i}}}^{+} \cdot(\overbrace{\frac{\partial q_{i}}{\partial b_{i}}}^{+} \cdot \overbrace{\frac{d b_{i}}{d k}}^{-}+\overbrace{\frac{\partial q_{i}}{\partial b_{j}}}^{-} \cdot \overbrace{\frac{d b_{j}}{d k}}^{-})
\end{aligned}
$$

As usual, there exist two different effects on profits of firm $i$ when $k$ changes. A direct effect that passes through a change in the quantity produced by firm $i$, and an indirect effect that is due to the change in the marginal willingness to pay of consumers when total supply varies. With regard to the former one, when $k$ goes up we observe a reduction in the incentive parameter (this means a reduction in the degree of competition or an increase in the degree of cooperation). This causes two opposite effects on $q_{i}$. In fact, the reduction in the degree of competition (alternatively, the increase in the degree of cooperation) of player $j$ (resp. player $i$ ) causes an increase (resp. a reduction) in $q_{i}$. Since this second effect dominates, we definitely observe a reduction in the quantity produced by firm $i$ as long as $k$ increases, so that profits reduce through this channel. With regard to the latter effect, we have that since the depressing effect of an increase in $k$ on quantities produced by firm $i$ and firm $j$ (due to a change in $b_{i}$ and $b_{j}$, respectively) is relatively strong, this causes an increase in market price that in turn induces an increase in profits. This positive effect on profits more than offsets the negative direct effect detailed above so that profits of firm $i$ definitely increases when for some exogenous reasons $k$ increases.

\subsection{The model with mixed behaviour}

We now assume that firm 1 hires a manager with a relative profit delegation contract $\left(b_{1} \neq 0\right)$ and firm 2 is profit maximising $\left(b_{2}=0\right)$. Then, at the market stage, we get:

$$
\frac{\partial u_{1}}{\partial q_{1}}=0 \Leftrightarrow q_{1}\left(q_{2}, b_{1}\right)=\frac{1-q_{2}\left(1-b_{1}\right)}{2},
$$

and

$$
\frac{\partial \Pi_{2}}{\partial q_{2}}=0 \Leftrightarrow q_{2}\left(q_{1}\right)=\frac{1-q_{1}}{2}
$$

From (34) and (35), we find that

$$
\bar{q}_{1}\left(b_{1}\right)=\frac{1+b_{1}}{3+b_{1}}
$$

and

$$
\bar{q}_{2}\left(b_{1}\right)=\frac{1}{3+b_{1}} .
$$

The bargaining stage involves only the owner and the manager of firm 1 since $b_{2}=0$, so that: 


$$
\frac{\partial \mathrm{N}_{1}}{\partial b_{1}}=0 \Leftrightarrow \frac{1-3 k-b_{1}(1+k)}{\left(3+b_{1}\right)^{3}\left(1+b_{1}\right)^{k}}=0 \Leftrightarrow b_{1}=\frac{1-3 k}{1+k},
$$

Then, the (asymmetric) equilibrium values of the bonus of player $1(\mathrm{RP})$ and player $2(\mathrm{PM})$ are

$$
b_{1}^{R P / P M}=\frac{1-3 k}{1+k}, \quad b_{2}^{R P / P M}=0 .
$$

As in the symmetric case in which both firms use relative profit delegation contracts, in this asymmetric case $-1<b_{1}^{R P / P M}<1$ and $b_{1}^{R P / P M}$ is a decreasing function of $k$. Given (39) equilibrium values of quantity, market price, profit of firm 1 (where the manager is hired with a relative profit delegation contract) and firm 2 (that is profit maximising) and manager 1's utility are given by

$$
q_{1}^{R P / P M}=\frac{1-k}{2}, \quad q_{2}^{R P / P M}=\frac{1+k}{4}, \quad p^{R P / P M}=\frac{1+k}{4},
$$

and

$$
\Pi_{1}^{R P / P M}=\frac{(1-k)(1+k)}{8}, \quad \Pi_{2}^{R P / P M}=\frac{(1+k)^{2}}{16} \text { and } u_{1}^{R P / P M}=\frac{(1+k)^{2}}{16} .
$$

By looking at Eqs. (40.1) and (40.2), we can see that $q_{1}^{R P / P M}$ (resp. $q_{2}^{R P / P M}$ ) is a decreasing (resp. increasing) function of $k$, and $q_{1}^{R P / P M}>q_{2}^{R P / P M}$ (resp. $q_{1}^{R P / P M}<q_{2}^{R P / P M}$ ) when $k<1 / 3$ (resp. $k>1 / 3$ ). In addition, $\Pi_{1}^{R P / P M}$ (resp. $\Pi_{2}^{R P / P M}$ ) is a decreasing (resp. increasing) function of $k$, and $\Pi_{1}^{R P / P M}>\Pi_{2}^{R P / P M}$ (resp. $\Pi_{1}^{R P / P M}<\Pi_{2}^{R P / P M}$ ) when $k<1 / 3$ (resp. $k>1 / 3$ ), whereas the utility of manager of firm 1 is a monotonic increasing function of $k$. When firm 1 competes (resp. colludes) with firm 2 an increase in the bargaining power $k$ acts as a disincentive (resp. incentive) for the manager of the delegated firm that actually produces less (resp. more) than the profit maximising rival does. In addition, profits of the delegated (resp. profit maximising) firm reduces (resp. increases) with $k$ because production of firm 1 (resp. firm 2) decreases (resp. increases). For the profit maximising firm, profits increase because both production and the marginal willingness to pay of consumers tends to increase with $k$. The differences of the effects of a change in $k$ on profits of the delegated firm 1 and the profit maximising firm 2 can be disentangled by taking the total derivative. Then, by considering the following generic profit functions of $k$ when only firm 1 uses relative profit contracts

$$
\Pi_{1}^{R P / P M}=\Pi_{1}^{R P / P M}\left\{p\left[q_{1}\left(b_{1}(k)\right), q_{2}\left(b_{1}(k)\right)\right], q_{1}\left(b_{1}(k)\right)\right\},
$$

and

$$
\Pi_{2}^{R P / P M}=\Pi_{2}^{R P / P M}\left\{p\left[q_{1}\left(b_{1}(k)\right), q_{2}\left(b_{1}(k)\right)\right], q_{2}\left(b_{1}(k)\right)\right\},
$$

and computing their total derivative with respect to $k$, we get:

$$
\frac{d \Pi_{1}^{R P / P M}}{d k}=\overbrace{\frac{\partial \Pi_{1}^{R P / P M}}{\partial p}}^{+}(\overbrace{\frac{\partial p}{\partial q_{1}}}^{-} \cdot \overbrace{\frac{\partial q_{1}}{\partial b_{1}}}^{+} \cdot \overbrace{\frac{d b_{1}}{d k}}^{\bar{z}}+\overbrace{\frac{\partial p}{\partial q_{2}}}^{-} \cdot \overbrace{\frac{\partial q_{2}}{\partial b_{1}}}^{\bar{n}} \cdot \overbrace{\frac{d b_{1}}{d k}}^{-})+\overbrace{\frac{\partial \Pi_{1}^{R P / P M}}{\partial q_{1}}}^{+} \cdot \overbrace{\frac{\partial q_{1}}{\partial b_{1}}}^{+} \cdot \overbrace{\frac{d b_{1}}{d k}}^{-},
$$

and

$$
\frac{d \Pi_{2}^{R P / P M}}{d k}=\overbrace{\frac{\partial \Pi_{2}^{R P / P M}}{\partial p}}^{+} \cdot(\overbrace{\frac{\partial p}{\partial q_{1}}}^{\bar{z}} \cdot \overbrace{\frac{\partial q_{1}}{\partial b_{1}}}^{+} \cdot \overbrace{\frac{d b_{1}}{d k}}^{\bar{z}}+\overbrace{\frac{\partial p}{\partial q_{2}}}^{-} \cdot \overbrace{\frac{\partial q_{2}}{\partial b_{1}}}^{\bar{n}} \cdot \overbrace{\frac{d b_{1}}{d k}}^{-})+\overbrace{\frac{\partial \Pi_{2}^{R P / P M}}{\partial q_{2}}}^{+} \cdot \overbrace{\frac{\partial q_{2}}{\partial b_{1}}}^{-} \overbrace{\frac{d b_{1}}{d k}}^{-} .
$$

The effects of an increase in $k$ on profits of the relative profit delegated firm 1 and the profit maximising firm 2 are different because of the different (direct) role played by a change in $k$ on the quantity produced. In fact, the effect of a change in $k$ on market price is the same for both firms (we recall that products are homogeneous). Indeed, the effect on market price can be detailed in the following way: an increase in $k$ reduces the incentive parameter of the delegated firm (that is, it reduces the degree of competition for any $k<1 / 3$ or it increases the degree of cooperation for any $k>1 / 3)$. This implies an increase in the quantity produced by the profit maximising firm. The 
market price, therefore, reduces through this channel. However, the reduction in the incentive parameter $b_{1}$ induce a reduction in the quantity produced by firm 1 . Then, the market price increases through this channel. Since this latter effect dominates on the former one, the market price and then profits of both firms increase as long as $k$ increases for some exogenous reasons. With regard to the direct effect of a change in $k$, we may observe a reduction (resp. increase) in the quantity produced by firm 1 (resp. firm 2) and then a subsequent reduction (resp. increase) in their own profits. Definitely, we may conclude that for the relative profit delegated firm 1 the depressing effect of the reduction in $q_{1}$ more than offsets the indirect effect on price detailed above, so that $\Pi_{1}^{R P / P M}$ reduces, whereas for the profit maximising firm 2 the positive effect of the increase in $q_{2}$ strengthens the effect of the increase in profits due to the higher market price.

\subsection{The contract-bonus stage with RP and PM}

We now add a third stage where players choose whether to play RP or PM by comparing profits under those strategies. Table 3 shows the payoff matrix that summarises the outcomes (profits) of RP versus PM.

Table 3. Payoff matrix: profits with relative profit delegation (RP) and profit maximisation (PM).

\begin{tabular}{|c|c|c|}
\hline Firm 1 & PM & RP \\
\hline PM & $\frac{1}{9}, \frac{1}{9}$ & $\frac{(1+k)^{2}}{16}, \frac{(1-k)(1+k)}{8}$ \\
\hline RP & $\frac{(1-k)(1+k)}{8}, \frac{(1+k)^{2}}{16}$ & $\frac{(3-k)(1+k)}{32}, \frac{(3-k)(1+k)}{32}$ \\
\hline
\end{tabular}

Then, the following proposition holds.

Proposition 5. [RP versus PM]. (1) If $0 \leq k<1 / 3$ then there exists a unique SPNE, that is (RP,RP), and it is Pareto inefficient. (2) If $1 / 3<k<1$ then there exists a unique SPNE, that is (PM,PM), and it is Pareto inefficient. In both cases, the game always boils down to the prisoner's dilemma paradigm.

Proof. Profit differentials are the following:

and

$$
\begin{aligned}
\Delta_{1} & =\Pi_{1}^{R P / P M}-\Pi_{1}^{P M / P M}=\frac{(1+3 k)(1-3 k)}{72}, \\
\Delta_{2} & =\Pi_{1}^{P M / R P}-\Pi_{1}^{R P / R P}=\frac{(1+k)(3 k-1)}{32}
\end{aligned}
$$

$$
\Delta_{3}=\Pi_{1}^{P M / P M}-\Pi_{1}^{R P / R P}=\frac{(5-3 k)(1-3 k)}{288} .
$$

The sign of $\Delta_{1}, \Delta_{2}$ and $\Delta_{3}$ changes depending on the size of the degree of bargaining. In particular, if $0 \leq k<1 / 3$ then $\Delta_{1}>0, \Delta_{2}<0$ and $\Delta_{3}>0$; if $1 / 3<k<1$ then $\Delta_{1}<0, \Delta_{2}>0$ and $\Delta_{3}<0$. Q.E.D.

Proposition 5 shows that the RP strategy cannot be the Nash equilibrium anymore when there exists a bargaining owner-manager over executive remuneration. In fact, since managers want to maximise their own objectives, they tend to reduce their own production and increase profits and the weight of the delegation component in their utility. When the relative bargaining power is sufficiently small $(0 \leq k<1 / 3)$, owners' profits weight relatively more than managers' utility in the Nash product, so that the final outcome of the contract-bonus stage is the standard result that $(\mathrm{RP}, \mathrm{RP})$ is the Pareto inefficient Nash equilibrium. In this case, both firms hire a manager and 
delegate output decisions to him (RP strictly dominates PM), and there is a unilateral incentive for each player to deviate from PM even if both players may actually coordinate to play pure profits. When $k$ becomes larger $(1 / 3<k<1)$, managers' utility weights relatively more than owners' profits in the Nash product and PM strictly dominates RP. This because profits of the delegated firm when the rival plays PM substantially reduces. Then, (PM,PM) becomes the Pareto inefficient Nash equilibrium of the game. Pareto inefficiency implies that there exists an incentive for both players to coordinate in order to deviate from PM and play RP (due to the colluding behaviour), but players still continue to play (PM,PM) as the game still boils down to the typical prisoner's dilemma paradigm. This means each player does have any unilateral incentive to deviate from RP. In this last case $(1 / 3<k<1)$, owners do not hire any managers.

The economic intuition behind the simultaneous change in the sign of the three profit differentials $\Delta_{1}, \Delta_{2}$ and $\Delta_{3}$ when $k$ crosses $1 / 3$ is the following. 1) $\left(\Delta_{1}\right)$ Since $\Pi_{1}^{P M / P M}$ does not depend on $k$, an increase in the relative bargaining power of the manager causes a reduction in the incentive parameter that, in turn, causes a reduction in $q_{1}$ as well as in total supply thus implying an increase in the market price and then in profits. Since $\partial \Pi_{1}^{R P / P M} / \partial k<0$ and $\Pi_{1}^{P M / P M}$ when $k$ becomes larger than 1/3 firm 1 loses the incentive to deviate from PM. 2) $\left(\Delta_{2}\right)$ When $k$ crosses $1 / 3$, we also observe a change in $\Delta_{2}$ that from negative becomes positive. This means that when firm 2 plays PM, firm 1 has the incentive to deviate from RP to PM. Therefore, in the two-strategy game RP versus PM there always exists a dominant strategy for any $0 \leq k<1$. In particular, when $0 \leq k<1 / 3$, RP strictly dominates PM, whereas when $1 / 3<k<1$ PM strictly dominates RP. Indeed, both $\Pi_{1}^{P M / R P}$ and $\Pi_{1}^{R P / R P}$ are increasing functions of $k$. However, the increase in $\Pi_{1}^{R P / R P}$ is larger than the increase in $\Pi_{1}^{P M / R P}$ when $k$ raises, so that for $k>1 / 3, \Pi_{1}^{P M / R P}$ dominates. 3) $\left(\Delta_{3}\right)$ When $k$ becomes relatively large, the increase in profits due to the increase in market price when both firms delegates is such that RP should be preferred to PM. However, since the game always has a strictly dominant strategy (RP when $k<1 / 3$ and PM when $k>1 / 3$ ), the Nash equilibrium still remains sub-optimal. Table 4 summarises the main findings of the two-strategy game RP versus PM when $k$ varies.

Table 4. Summary of the main results of RP versus PM.

\begin{tabular}{|c|c|c|}
\hline Efficiency & $\Pi_{i}^{P M / P M}>\Pi_{i}^{R P / R P}$ & $\Pi_{i}^{P M / P M}<\Pi_{i}^{R P / R P}$ \\
\hline $\mathrm{NE}$ & $(\mathrm{RP}, \mathrm{RP})$ & $(\mathrm{PM}, \mathrm{PM})$ \\
\hline$k$ & $0 \leq k<1 / 3$ & $1 / 3<k<1$ \\
\hline
\end{tabular}

\section{Sales delegation versus relative profit delegation}

In order to close the two-by-two comparison amongst the three different strategies S, RP and PM, in this section we take into account the two-strategy game $\mathrm{S}$ versus RP. To this purpose, we consider the behaviours of players when both firms are sales delegated, in which case the results of Section 3.1 hold, and the behaviours of players when both firms are relative profit delegated, in which case the results of Section 4.1 hold. Then, before playing the contract-bonus stage with $\mathrm{S}$ and RP, we need to account for the case of mixed behaviour. The next section is devoted to this issue and aims at clarifying the forces driving the choices of this kind of firms.

\subsection{The model with mixed behaviour}

In this section, we let firm 1 be sales delegated, so that the objective of manager 1 at the market stage is to maximise $u_{1}=\Pi_{1}+b_{1} q_{1}$ with respect to $q_{1}$, and firm 2 be relative profit delegated, so that the objective of manager 2 at the market stage is to maximise $u_{2}=\Pi_{2}-b_{2} \Pi_{1}$ with respect to $q_{2}$. Then, the reaction functions in this case are the following: 


$$
\frac{\partial u_{1}}{\partial q_{1}}=0 \Leftrightarrow q_{1}\left(q_{2}, b_{1}\right)=\frac{1-q_{2}+b_{1}}{2}
$$

and

$$
\frac{\partial u_{2}}{\partial q_{2}}=0 \Leftrightarrow q_{2}\left(q_{1}, b_{2}\right)=\frac{1-q_{1}\left(1-b_{2}\right)}{2} .
$$

From (41) and (42), we get quantities as function of both incentive parameters, that is:

$$
\bar{q}_{1}\left(b_{1}, b_{2}\right)=\frac{1+2 b_{1}}{3+b_{2}}
$$

and

$$
\bar{q}_{2}\left(b_{1}, b_{2}\right)=\frac{1+b_{2}-b_{1}\left(1-b_{2}\right)}{3+b_{2}} .
$$

In the bargaining stage, owners and managers of firm $i$ wish to maximise (7) with respect to $b_{i}$ by taking into account (43) and (44). This programme for firm 1 and firm 2 yield:

$$
\frac{\partial \mathrm{N}_{1}}{\partial b_{1}}=0 \Leftrightarrow b_{1}\left(b_{2}\right)=\frac{1+3 k-b_{2}(1-k)}{4\left(1+b_{2}\right)},
$$

and

$$
\frac{\partial \mathrm{N}_{2}}{\partial b_{2}}=0 \Leftrightarrow b_{2}\left(b_{1}\right)=\frac{\left(1-b_{1}\right)(1-3 k)}{1+k+b_{1}(3-k)} .
$$

By using together (45) and (46), we definitely get the optimal (asymmetric) equilibrium values of the incentive parameters when firm 1 is sales delegated and firm 2 is relative profit delegated, that is

$$
b_{1}^{S / R P}=\frac{2 k}{1+k},
$$

and

$$
b_{2}^{S / R P}=\frac{(1-k)(1-3 k)}{-k^{2}+8 k+1} .
$$

Then, the following proposition holds.

Proposition 6. For any $0 \leq k<1$, we have that $0 \leq b_{1}^{S / R P}<1$ and $b_{1}^{S / R P}$ monotonically increases with $k$. If $0 \leq k<1 / 3$ then $0<b_{2}^{S / R P}<1$ and $b_{2}^{S / R P}$ monotonically decreases with $k$. If $1 / 3<k<1$ then $-1<b_{2}^{S / R P}<0$ and $b_{2}^{S / R P}$ is a U-shaped function of $k$, with $k=3 / 5$ being a global minimum.

Proof. The proof easily follows from (47) and (48). Q.E.D.

In line with the results detailed in previous sections, when may play either $\mathrm{S}$ or RP the incentive parameter is always positive under $\mathrm{S}$ for any $0 \leq k<1$, whereas being positive (resp. negative) under RP depending on the size the manager's bargaining power. This implies that when $k$ is small (resp. large) enough, the owner that hires a manager with a relative profit contract wants that his manager competes (resp. colludes) with the manager hired by the rival with a sales delegation contract.

By using (44) and (45), equilibrium values of quantities, market price, profits and managers' utilities are the following:

$$
q_{1}^{S / R P}=\frac{-k^{2}+8 k+1}{4(1+k)}, \quad q_{2}^{S / R P}=\frac{(1-k)^{2}}{2(1+k)}, \quad p^{S / R P}=\frac{1-k^{2}}{4(1+k)}, \quad \Pi_{1}^{S / R P}=\frac{(1-k)\left(-k^{2}+8 k+1\right)}{16(1+k)},
$$

and 


$$
\Pi_{2}^{S / R P}=\frac{(1-k)^{3}}{8(1+k)}, \quad u_{1}^{S / R P}=\frac{\left(-k^{2}+8 k+1\right)^{2}}{16(1+k)^{2}} \quad \text { and } \quad u_{2}^{S / R P}=\frac{(1-k)^{2}(1+k)}{16(1+k)} .
$$

From (49.1) and (49.2) we may conclude that $q_{1}^{S / R P}$ (resp. $q_{2}^{S / R P}$ ) is a monotonic increasing (resp. decreasing) function of $k, \Pi_{1}^{S / R P}$ is an inverted U-shaped function of $k$ (with $k=1 / 3$ being a global maximum), $\Pi_{2}^{S / R P}$ is a monotonic decreasing function of $k$, and 1) $q_{1}^{S / R P}<q_{2}^{S / R P}$ and $\Pi_{1}^{S / R P}<\Pi_{2}^{S / R P}$ (resp. 2) $q_{1}^{S / R P}>q_{2}^{S / R P}$ and $\Pi_{1}^{S / R P}>\Pi_{2}^{S / R P}$ ) for any $k<0.08514$ (resp. $k>0.08514$ ).

We avoid analysing the effects of $k$ on managers' utilities as the equilibrium values of the incentive parameters are new asymmetric and then things are more complicated. However, similar arguments as those used in previous sections allows us to disentangle how $k$ affects profits of the sales delegated firm and the relative profit delegated firm. Then, by defining

$$
\Pi_{1}^{S / R P}=\Pi_{1}^{S / R P}\left\{p\left[q_{1}\left(b_{1}(k), b_{2}(k)\right), q_{2}\left(b_{1}(k), b_{2}(k)\right)\right], q_{1}\left(b_{1}(k), b_{2}(k)\right)\right\},
$$

and

$$
\Pi_{2}^{S / R P}=\Pi_{2}^{S / R P}\left\{p\left[q_{1}\left(b_{1}(k), b_{2}(k)\right), q_{2}\left(b_{1}(k), b_{2}(k)\right)\right], q_{2}\left(b_{1}(k), b_{2}(k)\right)\right\},
$$

as the generic profit function of both firms, their total derivative with respect to $k$ gives:

$$
\begin{aligned}
& \frac{d \Pi_{1}^{S / R P}}{d k}=\overbrace{\frac{\partial \Pi_{1}^{S / R P}}{\partial p}}^{+}[\overbrace{\frac{\partial p}{\partial q_{1}}}^{-} \cdot(\overbrace{\frac{\partial q_{1}}{\partial b_{1}}}^{+} \cdot \overbrace{\frac{d b_{1}}{d k}}^{+}+\overbrace{\frac{\partial q_{1}}{\partial b_{2}}}^{-} \cdot \overbrace{\frac{d b_{2}}{d k}}^{-})+\overbrace{\frac{\partial p}{\partial q_{2}}}^{-} \cdot(\overbrace{\frac{\partial q_{2}}{\partial b_{1}} \cdot \overbrace{\frac{d b_{1}}{d k}}^{+}+\overbrace{\frac{\partial q_{2}}{\partial b_{2}}}^{+} \cdot \overbrace{\frac{d b_{2}}{d k}}^{-})+}^{\overbrace{\frac{\partial \Pi_{1}^{S / R P}}{\partial q_{1}}}^{+}} \cdot(\overbrace{\frac{\partial q_{1}}{\partial b_{1}} \cdot}^{+} \cdot \overbrace{\frac{d b_{1}}{d k}}^{+}+\overbrace{\frac{\partial q_{1}}{\partial b_{2}}}^{-} \cdot \overbrace{\frac{d b_{2}}{d k}}^{-})
\end{aligned}
$$

and

$$
\begin{aligned}
& \frac{d \Pi_{2}^{S / R P}}{d k}=\overbrace{\frac{\partial \Pi_{2}^{S / R P}}{\partial p}}^{+}[\overbrace{\frac{\partial p}{\partial q_{1}}}^{-} \cdot(\overbrace{\frac{\partial q_{1}}{\partial b_{1}}}^{+} \cdot \overbrace{\frac{d b_{1}}{d k}}^{+}+\overbrace{\frac{\partial q_{1}}{\partial b_{2}}}^{-} \cdot \overbrace{\frac{d b_{2}}{d k}}^{-})+\overbrace{\frac{\partial p}{\partial q_{2}}}^{-} \cdot(\overbrace{\frac{\partial q_{2}}{\partial b_{1}} \cdot \overbrace{\frac{d b_{1}}{d k}}^{+}+\overbrace{\frac{\partial q_{2}}{\partial b_{2}}}^{+} \cdot \overbrace{\frac{d b_{2}}{d k}}^{-})]+}^{\overbrace{\frac{\partial \Pi_{2}^{S / R P}}{\partial q_{2}}}^{+}} \cdot(\overbrace{\frac{\partial q_{2}}{\partial b_{1}}}^{-} \cdot \overbrace{\frac{d b_{1}}{d k}}^{+}+\overbrace{\frac{\partial q_{2}}{\partial b_{2}}}^{+} \cdot \overbrace{\frac{d b_{2}}{d k}}^{-})
\end{aligned}
$$

Firm 1 (S versus RP). As usual, a change in the relative bargaining power of the manager affects both market price and quantity. With regard to the effect on market price, an increase in $k$ causes an increase in the incentive parameter $b_{1}$ and a reduction in the incentive parameter $b_{2}$. This produces an increase in $q_{1}$ that, in turn, tends to reduce market price. In addition, an increase in $k$ causes an ambiguous effect on $q_{2}$ and then on market price due to the increase in $b_{1}$ and the reduction in $b_{2}$. Nevertheless, the final effect of a change in $k$ on market price is always negative. This implies that the reducing effect on price due to the increase in $q_{1}$ always dominates the possible increasing effect on price due to the reduction in $q_{2}$. Then, profits of firm 1 reduces through this channel. However, there exists an additional (direct) positive effect of a change in $k$ on $\Pi_{1}^{S / R P}$ that passes through the increase in $q_{1}$. This last effect more than offsets the negative effects on profits due to the reduction in the market price, so that we definitely observe an increase in $\Pi_{1}^{S / R P}$ when $k$ goes up at least when $0 \leq k<1 / 3$, whereas when $1 / 3<k<1$ the depressing role played by the reduction on market price dominates so that $\Pi_{1}^{S / R P}$ reduces with $k$ in this last case. 
Firm 2 (S versus RP). The effect on $\Pi_{2}^{S / R P}$ of an increase in $k$ that passes through market price is the same as that previously discussed for profits of firm 1 . However, we now have an additional direct effect that passes through quantity $q_{2}$ that causes the reduction in profits. This effect contributes to definitely reduce profits of firm 2 monotonically when $k$ goes up.

\subsection{The contract-bonus stage with $S$ and $R P$}

We now look at whether players may play $\mathrm{S}$ or RP strategies in this two-by-two game. Table 5 shows the payoff matrix that summarises the outcomes (profits) of $\mathrm{S}$ versus RP.

Table 5. Payoff matrix: profits with relative profit delegation (RP) and profit maximisation (PM).

\begin{tabular}{|c|c|c|}
\hline Firm 1 & $\mathrm{S}$ & $\mathrm{RP}$ \\
\hline $\mathrm{S}$ & $\frac{2(1-k)(1+k)}{(3 k+5)^{2}}, \frac{2(1-k)(1+k)}{(3 k+5)^{2}}$ & $\frac{(1-k)[1+k(8-k)]}{16(1+k)}, \frac{(1-k)^{3}}{8(1+k)}$ \\
\hline RP & $\frac{(1-k)^{3}}{8(1+k)}, \frac{(1-k)[1+k(8-k)]}{16(1+k)}$ & $\frac{(3-k)(1+k)}{32}, \frac{(3-k)(1+k)}{32}$ \\
\hline
\end{tabular}

Then, the following lemma and proposition summarise the results.

Lemma 2. $\Pi_{i}^{R P / R P}>\Pi_{i}^{S / S}$ for any $0 \leq k<1$.

Proposition 7. [S versus RP]. (1) If $0 \leq k<0.1547$ then there exists a unique SPNE, that is (RP,RP), and it is Pareto efficient. (2) If $0.1547<k<0.1715$ then there exist two pure-strategy Nash equilibria, that is (RP,RP) and (S,S), and RP payoff-dominates S. (3) If $0.1715<k<1 / 3$ then there exists a unique SPNE, that is (S,S), and it is Pareto inefficient. In this case, the game falls within the typical prisoner's dilemma paradigm. (4) If $1 / 3<k<1$ then there exist two pure-strategy Nash equilibria, that is $(\mathrm{RP}, \mathrm{RP})$ and $(\mathrm{S}, \mathrm{S})$, and RP payoff-dominates $\mathrm{S}$.

Proof. Profit differentials are the following:

and

$$
\begin{gathered}
\Delta_{1}=\Pi_{1}^{S / R P}-\Pi_{1}^{R P / R P}=\frac{(3 k-1)\left(k^{2}-6 k+1\right)}{32(1+k)}, \\
\Delta_{2}=\Pi_{1}^{R P / S}-\Pi_{1}^{S / S}=\frac{(1-k)\left(3 k^{2}+6 k-1\right)\left(3 k^{2}-2 k-9\right)}{8(1+k)(3 k+5)^{2}},
\end{gathered}
$$

$$
\Delta_{3}=\Pi_{1}^{R P / R P}-\Pi_{1}^{S / S}=\frac{(11-3 k)(1+k)\left(3 k^{2}+12 k+1\right)}{32(3 k+5)^{2}}>0 .
$$

The sign of $\Delta_{1}$ and $\Delta_{2}$ changes depending on the size of the degree of bargaining. In particular, if $0 \leq k<0.1547$ then $\Delta_{1}<0, \Delta_{2}>0$ and $\Delta_{3}>0$; if $0.1547<k<0.1715$ then $\Delta_{1}<0, \Delta_{2}<0$ and $\Delta_{3}>0$; if $0.1715<k<1 / 3$ then $\Delta_{1}>0, \Delta_{2}<0$ and $\Delta_{3}>0$; if $1 / 3<k<1$ then $\Delta_{1}<0, \Delta_{2}<0$ and $\Delta_{3}>0$. Then, the proposition follows from Lemma 2 and these results. Q.E.D.

The outcomes of the game S versus RP are quite interesting, as they change three times when the bargaining power of managers increases. In fact, when $k$ is sufficiently small $(0 \leq k<0.1547)$, the Nash equilibrium of the game is (RP,RP) as $S$ is strictly dominated by RP. In addition, this Nash equilibrium is Pareto efficient, since firms do not have an incentive to deviate from RP, as profits associated with $\mathrm{S}$ are lower than profits associated with RP. When $k$ increases slightly, there is a window $(0.1547<k<0.1715)$ in which the game becomes a coordination one. This because $\mathrm{S}$ is no 
more strictly dominated by RP since when $k$ goes up we observe an increase in $\Pi_{1}^{S / R P}$ and $\Pi_{1}^{R P / R P}$ together with a reduction in $\Pi_{2}^{S / R P}$ and $\Pi_{1}^{S / S}$. When $k$ crosses 0.1547 , only $\Delta_{2}$ changes its sign (from positive it becomes negative), because the reduction in $\Pi_{1}^{S / S}$ is stronger than the reduction in $\Pi_{1}^{R P / S}$. In this case, there exists multiple pure-strategy Nash equilibria (S,S) and (RP,RP). A further increase in $k$ produces a dramatic change in the structure of the game. In fact, when $0.1715<k<1 / 3$ the contract-bonus game $\mathrm{S}$ versus RP becomes a prisoner's dilemma as the unique SPNE of the game is $(\mathrm{S}, \mathrm{S})$ and it is Pareto inefficient. Within this range of values of $k, \Pi_{i}^{S / S}$ reduces and $\Pi_{i}^{R P / R P}$ increases in such a way that $\mathrm{S}$ strictly dominates RP. Only $\Delta_{1}$ changes its sign (from negative it becomes positive), because the increase in $\Pi_{1}^{S / R P}$ is larger than the increase in $\Pi_{1}^{R P / R P}$ when $k$ increases. However, every firm has an incentive to deviate from $\mathrm{S}$ to $\mathrm{RP}$ since $\Pi_{i}^{R P / R P}>\Pi_{i}^{S / S}$. For $k>1 / 3, \Delta_{1}$ becomes negative given the substantial increase in $\Pi_{i}^{R P / R P}$, so that the contract-bonus game is again a coordination game.

Since when $0.1547<k<0.1715$ and $1 / 3<k<1$ there exist multiple equilibria in pure strategies, it is useful to consider mixed strategies. To this purpose, we define $x_{1}$ and $1-x_{1}$ (resp. $x_{2}$ and $1-x_{2}$ ) as the probabilities that firm 1 (resp. firm 2) plays either S or RP. Then, that a mixed-strategy Nash equilibrium is given by:

$$
x_{i}=x_{*}^{S / R P}=\frac{\Pi_{i}^{S / R P}-\Pi_{i}^{R P / R P}}{\left(\Pi_{i}^{S / R P}-\Pi_{i}^{R P / R P}\right)+\left(\Pi_{i}^{R P / S}-\Pi_{i}^{S / S}\right)}=\frac{(3 k+5)^{2}\left(1-9 k+19 k^{2}-3 k^{3}\right)}{9 k^{5}+93 k^{4}+198 k^{3}+174 k^{2}+49 k-11},
$$

where $i=1,2$. The study of (50) allows us to conclude that $x_{*}^{S / R P}>0$ only when $0.1547<k<0.1715$ and $k>1 / 3$. This probability is a decreasing (resp. increasing) function of $k$ for any $0.1547<k<0.1715$ (resp. $k>1 / 3$ ). In addition, $x_{*}^{S / R P} \rightarrow 1$ if $k \rightarrow 0.1547$ or if $k \rightarrow 1$ and $x_{*}^{S / R P}=0$ if $k=0.1715$ or $k=1 / 3$. This behaviour is in line with the results summarised in Proposition 7. In fact, for $k<0.1547$ there exists only one optimal Nash equilibrium, whereas when $0.1715<k<1 / 3$ the game is a prisoner dilemma.

The rules that comes from (50) can be summarised as follows: each firm will choose to play $\mathrm{S}$ (resp. RP) as a pure strategy if the rival plays $\mathrm{S}$ (resp. RP) with a probability $x>x_{*}^{S / R P}$ (resp. $x<x_{*}^{S / R P}$ ). If $0.1547<k<0.1715$ (resp. $k>1 / 3$ ), the higher $k$, the lower (resp. higher) the probability of playing RP as a pure strategy. By applying the Pareto dominance criterion and using Lemma 2, it is easy to verify that RP payoff-dominates S. Table 6 summarises the main findings of the two-strategy game RP versus $\mathrm{S}$ when $k$ varies.

Table 6. Summary of the main results of RP versus S.

\begin{tabular}{|c|c|c|c|c|}
\hline Efficiency & $\Pi_{i}^{R P / R P}>\Pi_{i}^{S / S}$ & $\Pi_{i}^{R P / R P}>\Pi_{i}^{S / S}$ & $\Pi_{i}^{R P / R P}>\Pi_{i}^{S / S}$ & $\Pi_{i}^{R P / R P}>\Pi_{i}^{S / S}$ \\
\hline $\mathrm{NE}$ & $(\mathrm{RP}, \mathrm{RP})$ & $(\mathrm{RP}, \mathrm{RP})$ and $(\mathrm{S}, \mathrm{S})$ & $(\mathrm{S}, \mathrm{S})$ & $(\mathrm{RP}, \mathrm{RP})$ and $(\mathrm{S}, \mathrm{S})$ \\
\hline$k$ & $0 \leq k<0.1547$ & $0.1547<k<0.1715$ & $0.1715<k<1 / 3$ & $1 / 3<k<1$ \\
\hline
\end{tabular}

\section{The endogenous game with three types of bonus}

In this section, we generalise the results of the models analysed in previous sections by allowing for the possibility that every player may actually play PM, S and RP. Table 7 summarises the payoff matrix that with profits related to each couple of strategies played by firm 1 and firm 2 in the contract-bonus stage. 
Table 7. Payoff matrix: profits in cases of profit maximisation (PM), sales delegation (S) and relative performance evaluation (RP).

\begin{tabular}{|c|c|c|c|}
\hline Firm 1 & PM & S & RP \\
\hline PM & $\frac{1}{9}, \frac{1}{9}$ & $\frac{(1-k)^{2}}{16}, \frac{(1-k)(1+k)}{8}$ & $\frac{(1+k)^{2}}{16}, \frac{(1-k)(1+k)}{8}$ \\
\hline S & $\frac{(1-k)(1+k)}{8}, \frac{(1-k)^{2}}{16}$ & $\frac{2(1-k)(1+k)}{(3 k+5)^{2}}, \frac{2(1-k)(1+k)}{(3 k+5)^{2}}$ & $\frac{(1-k)[1+k(8-k)]}{16(1+k)}, \frac{(1-k)^{3}}{8(1+k)}$ \\
\hline RP & $\frac{(1-k)(1+k)}{8}, \frac{(1+k)^{2}}{16}$ & $\frac{(1-k)^{3}}{8(1+k)}, \frac{(1-k)[1+k(8-k)]}{16(1+k)}$ & $\frac{(3-k)(1+k)}{32}, \frac{(3-k)(1+k)}{32}$ \\
\hline
\end{tabular}

In order to derive sub-game perfect Nash equilibria when $k$ varies, in addition to the concept of Nash equilibrium we also use the alternative method of iterated elimination of dominated strategies. As is known, a sub-game perfect equilibrium is a Nash equilibrium for the whole game as well as for each stage of the game. Since in the game summarised in Table 4 there are no strictly dominant strategies (only weakly dominant strategies do actually exist), we cannot use the concept of equilibrium in strictly dominant strategies to solve the game. The concept of equilibrium in dominant strategies is more restricting than that of Nash equilibrium, as it requires that all players have a dominant strategy, i.e. a strategy that is played no matter what the other player does. However, an equilibrium in dominant strategies is also a Nash equilibrium. Alternatively, the iterated elimination of dominated strategies is one common technique that may be applied here. In fact, strictly dominated strategies cannot be a part of a Nash equilibrium. This because it is irrational for any player to play them. It is important to note that the method of iterated elimination of dominated strategies holds as long as rationality among players is common knowledge (as is in our case). This means that every player knows that the rivals are rational, and each player knows that the rest of the players know that he knows that the rest of the players are rational, and so on ad infinitum. Rational players never play strictly dominated strategies. We can now state the following lemma and proposition.

Lemma 3. $\Pi_{i}^{P M / P M}>\Pi_{i}^{R P / R P}>\Pi_{i}^{S / S}$ for any $0 \leq k<1 / 3 . \Pi_{i}^{R P / R P}>\Pi_{i}^{P M / P M}>\Pi_{i}^{S / S}$ for any $1 / 3<k<1$.

Proposition 8. [Pure strategies]. (1) If $0 \leq k<0.1547$ there exists a unique SPNE, that is (RP,RP), and it is Pareto inefficient. The game is a prisoner's dilemma. (2) If $0.1547<k<0.1715$ there exist two pure-strategy Nash equilibria, that is (S,S) and (RP,RP), and S is payoff-dominated by RP. (3) If $0.1715<k<1 / 3$ there exists a unique SPNE, that is $(\mathrm{S}, \mathrm{S})$, and it is Pareto inefficient. The game is a prisoner's dilemma. (4) If $1 / 3<k<1$ there exist two pure-strategy Nash equilibria, that is (S,S) and (PM,PM), and $\mathrm{S}$ is payoff-dominated by $\mathrm{PM}$.

Proof. The proof comes by invoking the method of iterated elimination of dominated strategies.

Case $0 \leq k<0.1547$. Since PM is strictly dominated by S and RP for both players, it can be eliminated. As $\mathrm{S}$ is strictly dominated by RP for any player in the remaining two-by-two sub-game, it can be eliminated. Therefore, (RP,RP) is the unique pure-strategy Nash equilibrium. However, there exists an incentive for both players to coordinate towards PM (prisoner's dilemma). This because the payoff related to PM is the largest, but each player does not have any unilateral incentive to deviate from RP. The Nash equilibrium (RP,RP) is sub-optimal. 
Case $0.1547<k<0.1715$. Since PM is strictly dominated by S and RP for both players, it can be eliminated. In the remaining two-by-two sub-game, no other dominated strategies do exist. Then, a two-by-two comparison between $\mathrm{S}$ and RP allows us to conclude that $(\mathrm{S}, \mathrm{S})$ and $(\mathrm{RP}, \mathrm{RP})$ are the two pure-strategy Nash equilibria of the game. There would be an incentive for both players to coordinate themselves and play PM but unilaterally they do not.

Case $0.1715<k<1 / 3$. Since PM is strictly dominated by S and RP for both players, it can be eliminated. Then, since in the remaining two-by-two sub-game it holds that RP is strictly dominated by $\mathrm{S}$ for any player, it can be eliminated. Therefore, $(\mathrm{S}, \mathrm{S})$ is the unique pure-strategy Nash equilibrium. However, there exists an incentive for both players to coordinate towards PM (prisoner's dilemma) because the payoff related to it is the largest, but each player does not have any unilateral incentive to deviate from $\mathrm{S}$. The Nash equilibrium $(\mathrm{S}, \mathrm{S})$ is sub-optimal.

Case $1 / 3<k<1$. Since RP is strictly dominated by PM for both players, it can be eliminated. In the remaining two-by-two sub-game, no other dominated strategies do exist. Then, a two-by-two comparison between PM and S allows us to conclude that (PM,PM) and (S,S) are the two purestrategy Nash equilibria of the game. There would be an incentive for both players to coordinate themselves and play RP but unilaterally they do not.

Then, from Lemma 3 and these arguments, the proposition follows. Q.E.D.

As in the four intervals of $k$ detailed in Proposition 8 there always exist strictly dominated strategies (that will be played by rational players with probability zero), in order to identify mixedstrategy Nash equilibria we may concentrate on suitable two-by-two sub games. Now, let $x_{1}^{S}, x_{1}^{P M}$ and $x_{1}^{R P}=1-x_{1}^{S}-x_{1}^{P M}$ (resp. $x_{2}^{S}, x_{2}^{P M}$ and $x_{2}^{R P}=1-x_{2}^{S}-x_{2}^{P M}$ ) be the probabilities that firm 1 (resp. firm 2) plays S, PM and RP, respectively. By neglecting the probability profiles that identify purestrategy Nash equilibria and following the same procedure used in previous sections, for all parameters configuration supporting multiplicity of equilibria in pure strategies, there exists further mixed-strategy Nash equilibria. From these arguments, we can state the following result.

Proposition 9. [Mixed strategies]. (1) If $0.1547<k<0.1715$ then there exists a mixed-strategy Nash equilibrium $x_{1}^{S}=x_{2}^{S}=x_{*}^{S / R P}=\frac{(3 k+5)^{2}\left(1-9 k+19 k^{2}-3 k^{3}\right)}{9 k^{5}+93 k^{4}+198 k^{3}+174 k^{2}+49 k-11}$ and $x_{1}^{P M}=x_{2}^{P M}=0$. (2) If $1 / 3<k<1$ then there exists a mixed-strategy Nash equilibrium $x_{1}^{S}=x_{2}^{S}=x_{*}^{S / P M}=\frac{2(5+3 k)^{2}\left(9 k^{2}-1\right)}{(1+3 k)^{3}(13+3 k)}$ and $x_{1}^{R P}=x_{2}^{R P}=0$.

Table 8 summarises the main findings of the three-strategy game detailed in this section when $k$ varies.

Table 8. Summary of the main results of the three-strategy game PM, S and RP.

\begin{tabular}{|c|c|c|c|c|}
\hline Efficiency & $\Pi_{i}^{P M / P M}>\Pi_{i}^{R P / R P}>\Pi_{i}^{S / S}$ & $\Pi_{i}^{P M / P M}>\Pi_{i}^{R P / R P}>\Pi_{i}^{S / S}$ & $\Pi_{i}^{P M / P M}>\Pi_{i}^{R / R P}>\Pi_{i}^{S / S}$ & $\Pi_{i}^{R P / R P}>\Pi_{i}^{P M / P M}>\Pi_{i}^{S / S}$ \\
\hline $\mathrm{NE}$ & $(\mathrm{RP}, \mathrm{RP})$ & $(\mathrm{RP}, \mathrm{RP})$ and $(\mathrm{S}, \mathrm{S})$ & $(\mathrm{S}, \mathrm{S})$ & $(\mathrm{PM}, \mathrm{PM})$ and $(\mathrm{S}, \mathrm{S})$ \\
\hline$k$ & $0 \leq k<0.1547$ & $0.1547<k<0.1715$ & $0.1715<k<1 / 3$ & $1 / 3<k<1$ \\
\hline
\end{tabular}

When $0 \leq k<1 / 3$ and each player may choose amongst PM, S and RP, Nash equilibria of the game in pure strategies (whose normal form is summarised in Table 7) change when $k$ varies. The results of Jansen et al. (2009) are confirmed only for sufficiently low values of $k(0 \leq k<0.1547)$. In fact, in this case PM is strictly dominated by RP and the unique SPNE of the game is (RP,RP). However, this Nash equilibrium is Pareto inefficient as both firms would like to coordinate towards PM but 
each of them does not have a unilateral incentive to deviate (prisoner's dilemma). When $k$ increases, the scenario dramatically changes. In fact, for $0.1547<k<0.1715$, PM is strictly dominated by both $\mathrm{S}$ and RP, and the delegation game becomes a coordination game. There exist two pure-strategy Nash equilibria, given by $(\mathrm{S}, \mathrm{S})$ and $(\mathrm{RP}, \mathrm{RP})$ with the former being payoffdominated by the latter. The structure of the game changes again as $k$ continues to increase. In the range of values $0.1715<k<1 / 3$, the game becomes a prisoner's dilemma: PM is strictly dominated by $\mathrm{S}$ and the unique SPNE is $(\mathrm{S}, \mathrm{S})$. However, it is Pareto inefficient to design a sales delegation contract, because there exists an incentive for both firms to coordinate towards PM but no one has any unilateral incentive to deviate from S. Finally, when $1 / 3<k<1$ results are dramatically different from those pointed out by Jansen et al. (2009). In this case, in fact, the weight placed by each manager in the bargaining with the owner is relatively large and there is an incentive to collude under relative profit delegation. However, RP is strictly dominated by PM and then it will never be played. The game becomes a coordination game where the two pure-strategy Nash equilibria are $(\mathrm{S}, \mathrm{S})$ and $(\mathrm{PM}, \mathrm{PM})$, with the former being payoff-dominated by the latter.

\section{Consumers' surplus and social welfare}

This section tackles the issue of consumers' surplus and social welfare by comparing equilibrium outcomes under the alternative contracts PM, S and RP in the light of the results found in previous sections in the contract-bonus stage. In our context with linear demand, consumers' surplus ( $C S$ ) and social welfare $(W)$ are defined as follows: $C S=2 q^{2}$ and $W=2 \Pi+C S$. When the available contracts are PM, S and RP, the standard results in terms of $C S$ and $W$ of a managerial delegation game in which there is no bargaining owner-manager (and then only the owner chooses the incentive parameter) are summarised as follows.

Result 1. When only the owner chooses the incentive parameter $(k=0)$, we get $C S^{S / S}>C S^{R P / R P}>C S^{P M / P M}$ and $W^{S / S}>W^{R P / R P}>W^{P M / P M}$.

In contrast, in our bargaining model the following proposition holds.

Proposition 10. [Consumers' surplus and social welfare]. If $0<k<1 / 3$ then $C S^{S / S}>C S^{R P / R P}>C S^{P M / P M}$ and $W^{S / S}>W^{R P / R P}>W^{P M / P M}$. If $1 / 3<k<1$ then $C S^{S / S}>C S^{P M / P M}>C S^{R P / R P}$ and $W^{S / S}>W^{P M / P M}>W^{R P / R P}$.

Proof. Equilibrium values of consumers' surplus under (PM,PM), (S,S) and (RP,RP) are, respectively, the following: $C S^{P M / P M}=\frac{2}{9}, C S^{S / S}=\frac{8(1+k)^{2}}{(3 k+5)^{2}}$ and $C S^{R P / R P}=\frac{(3-k)^{2}}{32}$. Equilibrium values of social welfare under $(\mathrm{PM}, \mathrm{PM}),(\mathrm{S}, \mathrm{S})$ and $(\mathrm{RP}, \mathrm{RP})$ are, respectively, the following: $W^{P M / P M}=\frac{4}{9}, W^{S / S}=\frac{4(1+k)(3+k)}{(3 k+5)^{2}}$ and $W^{R P / R P}=\frac{(3-k)(5+k)}{32}$. Then, results easily follow by direct comparison amongst them. Q.E.D.

Proposition 10 tells us that (irrespective of the value of $k$ ) sales delegation represents the first best for both consumers and the society as a whole. However, contrasting the values of $C S$ and $W$ under $\mathrm{RP}$ and PM reveals that $C S^{P M / P M}>C S^{R P / R P}$ and $W^{P M / P M}>W^{R P / R P}$ if the bargaining power of the manager is sufficiently large. The conclusions of the received related literature are summarised in Result 2.

Result 2. When managers do not have any effect in determining the bonus $(k=0)$, consumers and the entire society are better off if each owner designs a sales delegation contract to his own 
manager. Unfortunately, in that case sales delegation (S) do not emerge as an endogenous Nash outcome, as the (inefficient) SPNE of the game is (RP,RP).

Therefore, the following question arises. Does the managers' bargaining power be harmful to social welfare or is it a useful instrument to increase it? An adequate welfare analysis can be performed only once the prevailing Nash equilibria of the game have been detailed depending on the value of $k$. This analysis would not have been possible when Nash equilibria were exogenously given. Figure 1 summarises the main findings, and shows a non-monotonic relationship between the strength of managerial bargaining power and the level of social welfare. These results, which are quite new at the best of our knowledge, may have clear policy consequences. In fact, the figure points out the existence of a plethora of different results as well as a socially optimal value of managerial power. It also shows that the society as a whole experiences its highest welfare when $k>0.1547$.

Case $0 \leq k<0.1547$. When (RP,RP) prevails as the unique SPNE of the game, social welfare $\left(W^{R P / R P}\right.$ ) is the second best for the society and it is a monotonic decreasing function of $k$. This because when $k$ goes up, both total supply and consumers' surplus reduce. This reduction more than offsets the increase in profits experienced by both firms.

Case $0.1547<k<0.1715$. The two pure-strategy Nash equilibria prevailing in this case are (S,S) and (RP,RP), the former being payoff-dominated by the latter, and there also exists one mixed-strategy Nash equilibrium, given by $x_{*}^{S / R P}$. Since this probability decreases as long as $k$ increases, we may conclude that the higher $k$, the lower the probability of playing RP as a pure strategy. The expected social welfare can be computed as a weighted combination between $W^{S / S}$ (that monotonically increases with $k$ ) and $W^{R P / R P}$ (that monotonically decreases with $k$ ) as follows:

$$
W_{e}^{S / R P}=W^{S / S}\left(1-x_{*}^{S / R P}\right)+W^{R P / R P} x_{*}^{S / R P} \text {. }
$$

It is a monotonic increasing function of $k$ since the probability of playing RP reduces when $k$ goes up. Therefore, the weight of $W^{R P / R P}$ (resp. $W^{S / S}$ ) in the expected welfare function reduces (resp. increases) with $k$ until it reaches the threshold $k=0.1715$. It is also important to note that the whole society is better off than when $k=0$ only whether the managerial bargaining power exceeds the threshold $\widetilde{k}_{W}$, where $\widetilde{k}_{W}:=0.1618$.

Case $0.1715<k<1 / 3$. When (S,S) prevails as the unique pure-strategy SPNE of the game, social welfare $\left(W^{S / S}\right)$ is the first best for the whole society and it monotonically increases with $k$. In fact, when $k$ goes up total supply increases, and this in turn causes an increase in the consumers' surplus that more than offsets the reduction in profits experienced by both firms.

Case $1 / 3<k<1$. Coherently with the results on Nash equilibria, (RP,RP) is never a Nash equilibrium within this range if values of $k$. Indeed, there actually exist two pure-strategy Nash equilibria, given by $(\mathrm{S}, \mathrm{S})$ and $(\mathrm{PM}, \mathrm{PM})$, the former being payoff-dominated by the latter, and one mixed-strategy Nash equilibrium, given by the probability $x_{*}^{S / P M}$. Since this probability increases with $k$, we may conclude that the higher $k$, the higher the probability of playing PM as a pure strategy. In this case, the expected social welfare can be computed as a combination that weights $W^{S / S}$ (that monotonically increases with $k$ ) and $W^{P M / P M}$ (which is a constant) according to the formula:

$$
W_{e}^{S / P M}=W^{S / S}\left(1-x_{*}^{S / P M}\right)+W^{P M / P M} x_{*}^{S / P M} .
$$

It is a monotonic decreasing function of $k$ since the probability of playing $\mathrm{S}$ reduces when $k$ goes up. Therefore, the weight of $W^{S / S}$ (resp. $W^{P M / P M}$ ) in the expected welfare function reduces (resp. increases) with $k$ until it reaches the threshold $k=1$. In this case, it is interesting to note that the 
society as a whole is worse off than when $k=0$ only whether the managerial bargaining power exceeds the threshold $\bar{k}_{W}$, where $\bar{k}_{W}:=0.498$.

Definitely, a policy recipe should prescribe to set $k=1 / 3$ and get the highest possible social welfare.

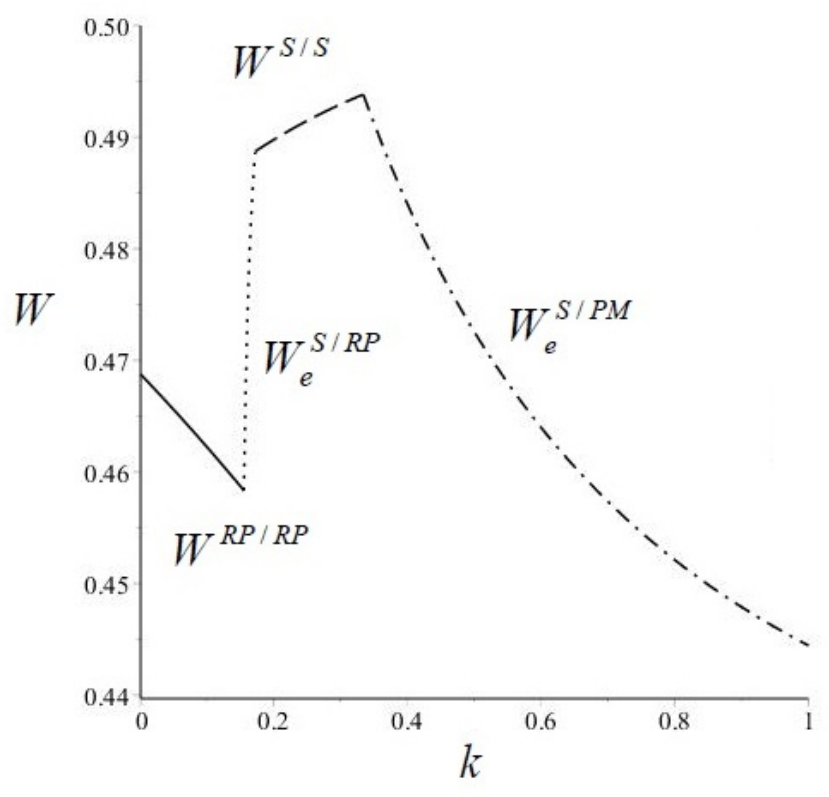

Figure 1. Social welfare when $k$ varies.

\section{Conclusions}

This article challenges the results of the "classical" managerial delegation literature led by Vickers (1985), Fershtman and Judd (1987), Sklivas (1987), who adopt sales or revenue delegation (S), and Miller and Pazgal (2002), who adopt relative profit delegation (RP), by introducing a bargaining mechanism between owners and managers over managerial contracts (van Witteloostuijn et al., 2007). The existence of a certain influence of the managerial power in designing the contracts has been increasingly witnessed by theoretical, empirical and policy arguments in recent years.

The existing literature on managerial delegation - which is essentially based on the assumption that the owner makes a take-it-or-leave-it offer to his manager when designing executive compensation contracts - found that $\mathrm{S}$ and RP are, respectively, the unique sub-game perfect Nash equilibrium choice for firms when they are singularly contrasted against pure profit maximisation (PM). In addition, by taking into account the endogenous comparison amongst all the types of contracts (i.e., pure profits, sales, market share and relative profit delegation), Jansen et al. (2009, 2012) and Manasakis et al. (2011) concluded that RP is the dominant strategy. This article challenges these results even in the case of a small managerial bargaining power. In particular, when only one type of bonus is contrasted against PM, as in VFJS (S versus PM) or Miller and Pazgal (RP versus PM), our results change the traditional view in each case. In particular, when the managerial strength in the owner-manager bargaining is about one third, the delegation game $\mathrm{S}$ versus PM from a prisoner's dilemma paradigm becomes a coordination game, whereas the typical prisoner's dilemma of the game RP versus PM is reverted, implying that no delegation endogenously emerges and this choice is Pareto inefficient. If $\mathrm{S}$ is contrasted with RP, the structure of the game changes even three times as long as the managers' power in the bargaining process 
increases. In particular, outcomes vary starting from a unique pure-strategy Pareto-efficient Nash equilibrium, given by (RP,RP), when managers have a sufficiently small bargaining power. Then, the game becomes towards a coordination game with two pure-strategy Nash equilibria, (RP,RP) and $(\mathrm{S}, \mathrm{S})$, for slightly higher values of the managerial power. It resembles the prisoner's dilemma paradigm with $(\mathrm{S}, \mathrm{S})$ being the unique pure-strategy Nash equilibrium for an intermediate range of values of the manager's power and, finally, the delegation games returns to be a coordination game with two pure-strategy Nash equilibria when the bargaining power of managers is sufficiently large.

Finally, when firms may choose amongst PM, S and RP, the outcomes of our endogenous delegation game sharply change the preceding wisdom that RP is a dominant strategy. Moreover, any equilibrium is always Pareto-inefficient. For instance, rather paradoxically, when the choice of no delegating ensures the highest profits, the Nash equilibrium is (RP,RP), whereas when RP ensures the highest profits, relative profits contracts cannot be part of a strategy profile leading to a Nash equilibrium.

The welfare analysis also shows that by taking appropriately into account the Nash equilibria of the game, consumers' surplus and social welfare depend on the strength of managerial power in a non-monotonic way. Interestingly, there also exists an "optimal" value of it, with straightforward policy implications. Therefore, since our main results crucially depend on the existence of a certain managerial influence in determining delegation contracts, we show that the possible increase in it, theoretically and empirically observed in the recent decades, may lead to a relevant change in the common wisdom based on the VFJS's approach as well as in the business world. Finally, we note that the results of this article qualitatively hold also in the case the bargaining owner-manager includes full contract details (i.e., fixed wage, bonus rate and weight of the bonus), as in Kopel et al. (2016).

Acknowledgements The authors gratefully acknowledge an anonymous reviewer for comments on an earlier draft. The usual disclaimer applies.

\section{References}

Aggarwal RK, Samwick AA. 1999. Executive compensation, strategic competition, and relative performance evaluation: theory and evidence. Journal of Finance 54: 1999-2043.

Aoki M. 1980. A model of the firm as a stockholder employee cooperative game. American Economic Review 70: 600-610.

Baumol W. 1958. On the theory of oligopoly. Economica 25: 187-198.

Bebchuk LA, Fried JM. 2003. Executive compensation as an agency problem. Journal of Economic Perspectives 17: 71-92.

Bebchuk LA, Fried JM. 2004. Pay without Performance. The Unfulfilled Promise of Executive Compensation. Cambridge (MA) US: Harvard University Press.

Bebchuk LA, Grinstein, Y. 2005. The growth of executive pay. Oxford Review of Economic Policy 21: 283-303.

Bebchuk LA, Fried JM, Walker DI. 2002. Managerial power and rent extraction in the design of executive compensation. University of Chicago Law Review 69: 751-846.

Binmore K, Rubinstein A, Wolinsky A. 1986. The Nash bargaining solution in economic modelling. RAND Journal of Economics 17: 176-188. 
Bughin J. 1995. Unions and strategic managerial incentives. Economics Letters 47: 95-100.

Correa-López M, Naylor RA. 2004. The Cournot-Bertrand profit differential: a reversal result in a differentiated duopoly with wage bargaining. European Economic Review 48: 681-696.

Cyert R, March J. 1963. Behavioral Theory of the Firm. Englewood Cliffs (NJ): Prentice-Hall.

Dixit AK. 1979. A model of duopoly suggesting a theory of entry barriers. Bell Journal of Economics 10: 20-32.

Fershtman C. 1985. Managerial incentives as a strategic variable in duopolistic environment. International Journal of Industrial Organization 3: 245-253.

Fershtman C, Judd KL. 1987. Equilibrium incentives in oligopoly. American Economic Review 77: 927-940.

Gibbons R, Murphy KJ. 1990. Relative performance evaluation for chief executive officers. Industrial and Labor Relations Review 43: 30S-51S.

Häckner J. 2000. A note on price and quantity competition in differentiated oligopolies. Journal of Economic Theory 93: 233-239.

Holmström B. 1982. Moral hazard in teams. Bell Journal of Economics 13: 324-340.

Inderst R. 2002. Contract design and bargaining power. Economics Letters 74: 171-176.

Jansen T, van Lier A, van Witteloostuijn A. 2007. A note on strategic delegation: the market share case. International Journal of Industrial Organization 25: 531-539.

Jansen T, van Lier A, van Witteloostuijn A. 2009. On the impact of managerial bonus systems on firm profit and market competition: the cases of pure profit, sales, market share and relative profits compared. Managerial and Decision Economics 30: 141-153.

Jansen T, van Lier A, van Witteloostuijn A. 2012. Managerial bonus systems in a differentiated duopoly: a comment. Managerial and Decision Economics 33: 61-70.

Jensen MC, Murphy KJ. 1990. Performance pay and top management incentives. Journal of Political Economy 98: 225-264.

Joh SW. 1999. Strategic managerial incentive compensation in Japan: relative performance evaluation and product market collusion. Review of Economics and Statistics 81: 303-313.

Kamaga K, Nakamura Y. 2008. Bargaining over managerial contracts in delegation games: the sequential move case. Economics Bulletin 12: 1-8.

Kopel M, Pezzino M, Ressi A. 2016. Location choice and contract bargaining. Managerial and Decision Economics 37: 140-148.

Lambert RA, Larcker DF, Weigelt K. 1991. How sensitive is executive compensation to organizational size. Strategic Management Journal 12: 395-402. 
Leibenstein H. 1979. A branch of economics is missing: micro-micro theory. Journal of Economic Literature 17: 477-502.

Manasakis C, Mitrokostas E, Petrakis E. 2011. Endogenous managerial incentive contracts in a differentiated duopoly, with and without commitment. Managerial and Decision Economics 31: $531-543$.

Merzoni GS. 2003. Strategic Delegation in Firms and the Trade Union. Berlin: Springer.

Miller N, Pazgal A. 2002. Relative performance as a strategic commitment mechanism. Managerial and Decision Economics 23: 51-68.

Nakamura Y. 2008a. Bargaining over managerial contracts in delegation games: the differentiated goods case. Economics Bulletin 12: 1-8.

Nakamura Y. 2008b. Bargaining over managerial contracts in delegation games: the quadratic cost case. Economics Bulletin 12: 1-7.

Nash JF. 1950. The bargaining problem. Econometrica 28: 155-162.

Ritz RA. 2008. Strategic incentives for market share. International Journal of Industrial Organization 26: 586-597.

Roth AE. 1979. Axiomatic models of bargaining. Lecture notes in economics and mathematical systems 170, Berlin: Springer.

Salas Fumás V. 1992. Relative performance evaluation of management. International Journal of Industrial Organization 10: 473-489.

Simon HA. 1964. On the concept of organizational goal. Administrative Science Quarterly 9: 1-21.

Singh N, Vives X. 1984. Price and quantity competition in a differentiated duopoly. RAND Journal of Economics 15: 546-554.

Sklivas SD. 1987. The strategic choice of managerial incentives. RAND Journal of Economics 18: 452-458.

Szymanski S. 1994. Strategic delegation with endogenous costs. A duopoly with wage bargaining. International Journal of Industrial Organization 12: 105-116.

van Witteloostuijn A. 1998. Bridging behavioral and economic theories of decline: organizational inertia, strategic competition, and chronic failure. Management Science 44: 501-519.

van Witteloostuijn A, Jansen T, van Lier A. 2007. Bargaining over managerial contracts in delegation games: managerial power, contract disclosure and cartel behaviour. Managerial and Decision Economics 28: 897-904.

Vickers J. 1985. Delegation and the theory of the firm. Economic Journal 95: 138-147. 
Managerial delegation theory revisited

Wang LFS, Wang YC, Zhao W. 2008. Strategic trade policy in bargaining over managerial delegation competition. Economics Bulletin 6: 1-8.

Williamson OE. 1964. The Economics of Discretionary Behavior: Managerial Objectives in a Theory of the Firm. Englewood Cliffs (NJ) US: Prentice-Hall. 